\title{
The arrested Agulhas retroflection
}

\author{
by Doron Nof ${ }^{1,2,3}$, Volodymyr Zharkov ${ }^{4}$, Joseph Ortiz ${ }^{5}$, Nathan Paldor ${ }^{6}$, \\ Wilton Arruda ${ }^{1,7}$ and Eric Chassignet ${ }^{4}$
}

\begin{abstract}
Paleoceanographic proxy data indicate that the Agulhas leakage into the South Atlantic was dramatically reduced during glacial times. In our former papers, we suggested that this was due to a northward shift of the zero wind stress curl that, in turn, forced the retroflection to occur farther north, where the slant of the coastline relative to the north is steep. In the present paper, we propose that strong westerlies ( $0.4 \mathrm{~Pa}$, implying a wind speed of $\sim 12 \mathrm{~m} \mathrm{~s}^{-1}$ at zero degrees centigrade), which were supposedly common during glaciations, can also arrest the leakage. This arrest occurred because the wind stress opposed the momentum flux associated with the retroflection; such an arrest did not require the retroflection to shift in latitude.

We use a simple, nonlinear, "reduced gravity" model to show analytically and numerically that, under the above conditions, the eastward wind stress compensates for the zonal westward flow-force associated with the retroflection, thus avoiding the development and shedding of rings. For a nearly zonal wall, westerly winds, and small upper layer thickness along the wall, the arresting wind stress is found, theoretically, to be, $\tau^{x}=0.042 \alpha^{3 / 2} \rho f_{0}\left[\left(2 f_{0} Q\right)^{3} / g^{\prime}\right]^{1 / 4}$, where $\alpha$ is twice the retroflection eddy vorticity, $\rho$ is the water density, $Q$ is the Agulhas Current volume flux, and the remaining notation is conventional.
\end{abstract}

\section{A few words on Stern's contribution to the field of eddies}

Eddies, the oceanic analogs of tornadoes and hurricanes, were one of Melvin's specialties. In an elegant paper that most people originally referred to as "esoteric" (1974, JMR), Melvin showed that much can be learned about eddies by looking at groups of two adjacent vortices, each spinning in a different direction. For reasons known only to him, he coined this counter-spinning vortex a "Modon". (A modon actually means a collection of cities in Arabic.) Despite the initial skepticism by some (evidently, one editor of a respectable

1. Department of Earth, Ocean and Atmospheric Science, Florida State University, Tallahassee, Florida, 32306, U.S.A.

2. Geophysical Fluid Dynamics Institute, Florida State University, Tallahassee, Florida, 32306, U.S.A.

3. Corresponding author. email: doron@fsu.edu

4. Center for Oceanic-Atmospheric Prediction Studies, Florida State University, Tallahassee, Florida, 32306, U.S.A.

5. Department of Geology, Kent State University, Kent, Ohio, 44242, U.S.A.

6. Department of Atmospheric Science, The Hebrew University of Jerusalem, Jerusalem, Israel.

7. Instituto de Matemática, Universidade Federal do Rio de Janeiro (UFRJ), Rio de Janeiro, RJ, Brazil. 
physical oceanographic journal told Melvin that he would have "never" published that paper), this paper spun up many generations of observations and theory for decades after its publication.

\section{Introduction}

In our earlier articles (Zharkov and Nof, 2008a.b; ZNab, hereafter), we argued that the shutoff of Agulhas ring shedding during glacial periods (suggested by paleoceanographic proxy data) was probably caused by a northward shift of the retroflection position. Specifically, a northward shift of the zero wind stress curl (WSC) caused migrations of the retroflection to regions where the coastline has what we termed "supercritical coastline slant." Because of its almost north-south orientation, the coast significantly slows the $\beta$-induced westward propagation speed of the rings. In such regions, the westward propagation of the newly detached eddy is not fast enough to escape from the next ring generated behind. Therefore, the eddy is re-captured by the ring following immediately behind it or by a meander of the retroflected current.

While this seems plausible, we suggest here that the strength of the wind-stress itself, which intensified significantly during glacial periods because of a reduced friction on the ground, could also affect the ring-shedding regimes dramatically. Such a response has been suggested on the basis of sediment provenance studies (Franzese et al., 2006). [Note that the amplification of Southern Hemisphere latitudinal and precessional insolation (Esper et al., 2004) also contributes to the strengthening of glacial winds.] Surprisingly, the Agulhas Current itself was not enhanced during glaciation (Franzese et al., 2006) even though the wind stress increased (e.g., Shulmeister et al., 2004; Butzin et al., 2005; Anderson et al., 2009; Pichevin et al., 2005). This is probably because the Indian Ocean is open (to the south, northeast and southeast) so the familiar concept that the western boundary current (WBC) is equal and opposite to the Sverdrup interior does not hold. This is reflected in Casal et al. (2009) who showed that, at present, not only the Sverdrup Transport (ST), but also the Indonesian Throughflow and the Indian Ocean overturning, contribute to the mass budget of the AC current. During glacials, the relationship between these three components may have been different, so that an increase in ST did not directly transmit to a change in the Agulhas influx.

We show that, if the wind is sufficiently strengthened, the shutoff could occur even when the point of retroflection is located near the coast with a nearly critical, but not supercritical, slant. The idea of a retroflection arrest due to stronger westerlies is consistent with recent observations of eastward propagating eddies in the South China Sea. Apparently, during the summer monsoon, the wind that blows toward the east is so strong that it overcomes the $\beta$-induced westward migration tendency and forces the eddies eastward [see Fig. 10 in Xiu et al. (2010) and, for general eddies structure in the South China Sea, see Nan et al. (2011)]. This is very similar to what we are proposing here regarding the Agulhas retroflection whose eddies' westward migration is inhibited. 


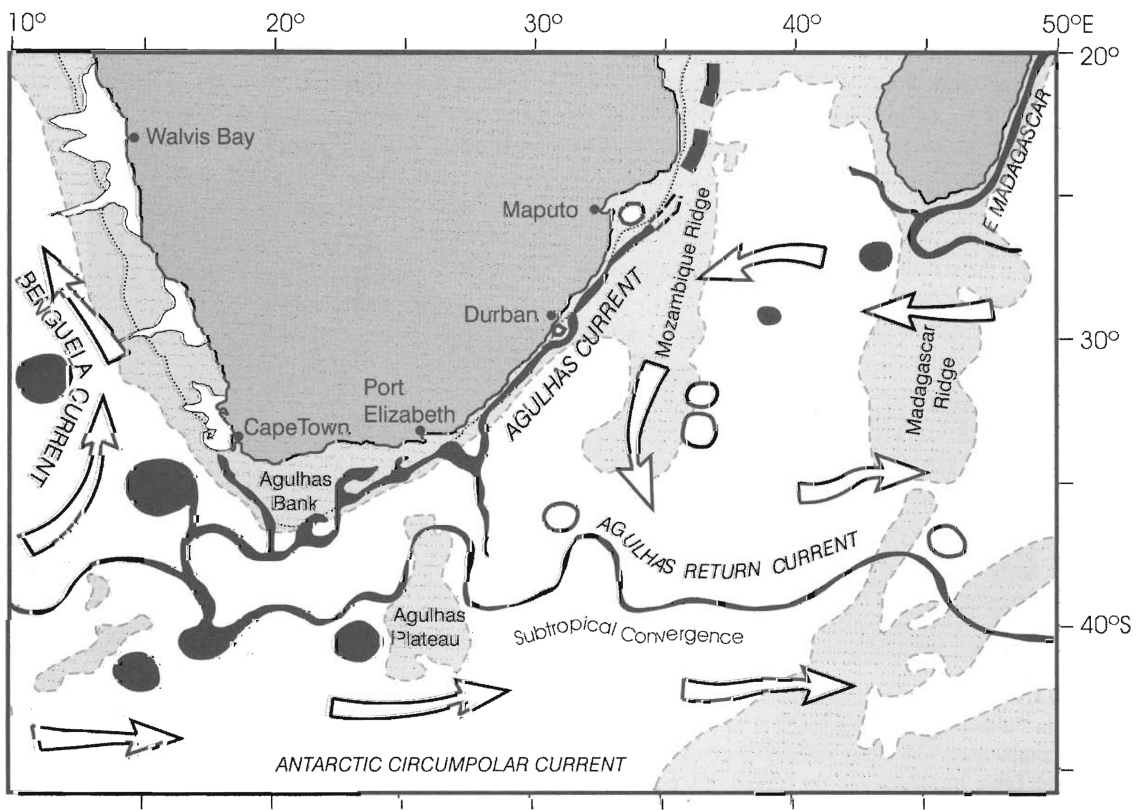

Figure 1. A conceptual portrayal of the present-day Agulhas Current system. Areas shallower than $3000 \mathrm{~m}$ are shaded. The edge of the continental shelf is represented by the dotted line at the $500 \mathrm{~m}$ isobath. Intense currents and their component parts are black; the general background circulation is indicated by open arrow. Cyclonic eddies are open; anticyclonic rings and eddies are black. Adapted from Lutjeharms (2006).

\section{a. Present day observations}

Several observations and numerical models show that variations of the Agulhas inflows, particularly those caused by shed rings, significantly affect the decadal variability in the Atlantic meridional overturning cell and various models confirm this (Weijer et al., 1999, 2002; Biastoch et al., 2008, 2009; Beal et al., 2011). In a closed basin, WBCs separate (or retroflect) at the same latitude of the zero WSC because their transport is equal and opposite to that of the Sverdrup interior. In the case of the Agulhas Current (Fig. 1), the Indian Ocean basin is not closed (it is open to the Atlantic in the southwest), so the WBC can separate north or south of the zero WSC. Indeed, the wind stress curl vanishes at about $45^{\circ} \mathrm{S}$, whereas the Agulhas Return Current flows between $38^{\circ} \mathrm{S}$ and $41^{\circ} \mathrm{S}$ and shifts slightly to the north during earlier retroflection events. Still, the main cause of Agulhas retroflection is the vanishing WSC farther south (as it is for other WBCs) because there can be no returning interior (Sverdrup) flow past that latitude.

Typically, Agulhas rings are shed at a frequency of 5-6 per year, although there have been periods of almost half a year when no shedding event was observed (e.g., Gordon et al., 1987; Byrne et al., 1995; Schouten et al., 2000; Lutjeharms, 2006; Van Aken et al., 
2003; Dencausse et al., 2010a,b). This increased length of the shedding period is possibly associated with retroflections farther to the east (De Ruijter et al., 2004), but the possible effect of wind stress on such events has not been studied.

Presently, the typical winds in the Agulhas region are westerlies, whose speed is about $5 \mathrm{~m} \mathrm{~s}^{-1}$ (see, e.g., Rouault et al., 2009). The wind stress can be calculated by the bulk formula $\tau_{s}=\rho_{A} C_{D A} U^{2}$, where $\rho_{A}$ is the air density and $C_{D A}$ is the drag coefficient. Typical values for $\rho_{A}$ and $C_{D A}$ are $1.3 \mathrm{~kg} \mathrm{~m}^{-3}$ (at zero degree centigrade or somewhat colder) and 0.002 (the low limit in the familiar 0.002-0.0025 range). In this case, $\tau_{s}=0.08 \mathrm{~Pa}$, which is apparently too small to affect ring shedding. However, some authors use values as high as $0.2 \mathrm{~Pa}$ (see, e.g., Dijkstra and De Ruijter, 2001a) and, according to Kutsuvada et al. (2004), present day wind stress can reach, and even exceed, $0.3 \mathrm{~Pa}$. (Note that the maximal wind stress associated with these high values is situated farther to the south, at about $52^{\circ} \mathrm{S}$.)

\section{b. Paleoceanographic proxies}

Otto-Bliesner et al. (2006) suggested that, during the Last Glacial Maximum (LGM), the wind stress was about $0.25 \mathrm{~Pa}$ in the Southeastern Atlantic, so the wind stress in the more active Agulhas region is taken to be $0.4 \mathrm{~Pa}$. This corresponds to a glacial wind of $12 \mathrm{~m} \mathrm{~s}^{-1}$. Here, we again use a $C_{D A}$ of 0.002 , which is perhaps a bit high for fast winds (see, e.g., Morey et al., 2005), but is adequate for a slightly unstable atmosphere such as the one above the warm Agulhas Current.

The above choice of stress is supported by several other studies. Shulmeister et al. (2004) infer increased wind stress in the Australian sector of the Antarctic Circumpolar Current during glacial stages as well. Butzin et al. (2005) produced plausible reconstructions of the glacial radiocarbon field with an enhanced wind configuration that reached amplitudes twice as big as those of the modern winds in high southern latitudes (see their Fig. 7). Anderson et al. (2009) suggested that there was a strong intensification of Ekman upwelling (six times the modern value in the Atlantic and probably in the Agulhas region), implying that the wind stress could reach about $0.4 \mathrm{~Pa}$ or even higher. Furthermore, Pichevin et al. (2005) corroborated this view, noting that aeolian dust recovered from a core raised from the Namibian upwelling zone indicates a strong inverse correlation between enhanced winds and SST, evidence of greater upwelling during glacial periods, particularly in marine isotope stages 3 and $4(\sim 30-85 \mathrm{ka})$. They found no evidence of incursions of warm, poleward waters during glacial stages prior to early stage $6(\sim 160-190 \mathrm{ka})$.

In addition, it was tentatively suggested even earlier that Agulhas rings shedding was shut off during glacials (Howard and Prell, 1992; Berger and Wefer, 1996; Flores et al., 1999; Rau et al., 2002; Peeters et al., 2004). Pether (1994) found evidence for enhanced Agulhas advection into the Benguela Current during the initial deglaciation (as the system transitioned into the modern state). Esper et al. (2004), employing fossil plant assemblages and pollen records from a core off the Cape-of-Good-Hope, reached similar conclusions. They noted that greater upwelling intensity, postulated to occur in response to an equatorward shift of the maximal wind stress, in fact occurred in response to greater seasonality 
associated with stronger precessional forcing. Although our original idea $(\mathrm{ZNa}, \mathrm{b})$ was that this shutoff occurred primarily because of the northward shift of the wind bands, it is interesting to investigate whether the increasing intensity of the wind stress itself (with no change in the WSC position) could be a second cause.

\section{c. Theoretical background}

According to Nof and Pichevin (1996), rings are generated to compensate for the eastward retroflecting current momentum flux. Also, Zharkov and Nof (2008a; ZNa, hereafter) pointed out a vorticity paradox: only rings with strong relative vorticity satisfy the equations of momentum and mass conservation. One way to avoid this paradox is to focus on currents retroflecting near coastlines with slants greater than a threshold value $\left(\sim 15^{\circ}\right)$. $\mathrm{ZNb}$ and Zharkov et al. (2010) elaborated on the effect of coastal geometry on ring shedding for one-and-a-half layer models with slanted and kinked coastlines. They showed that, in the case of a rectilinear coast, there is a critical value of a slant above which there is almost no shedding. These results are in agreement with the numerical runs shown in Pichevin et al. (2009).

In virtually all of the earlier modeling efforts the wind stress (with its vanishing curl) was considered only as a general basin-wise cause of current retroflection. The wind forcing itself directly over the retroflection was assumed negligible in comparison with inertial terms, Coriolis force, and reduced gravity forcing. Recently, Chang and Oey (2010) showed the significant effect of wind on Loop Current ring shedding in the Gulf of Mexico, where the typical values of wind stress are about $0.2 \mathrm{~Pa}$, suggesting that it may also be important to the Agulhas.

\section{d. Present approach}

Here, we consider the wind stress terms in the equations of motion for the retroflection region and show that the effect of the enhanced winds could cause a significant reduction of the ring-induced leakage during glacials. We have tried to make this paper as selfcontained as possible-we listed the most important equations of the previous works (ZNa,b and Zharkov et al., 2010), so that the reader is able to follow the main steps of our theory. The paper is organized as follows. In Section 2, we introduce the governing equations that control the development of the base eddy (BE) in windy conditions, and discuss the terms that should be added to the governing equations used in our earlier no-wind papers (ZNa,b). The theoretical analysis of these equations is given in Section 3. In Section 4, we present model solutions for slanted and kinked coastlines and their dependence on the vorticity and slant. Section 5 is devoted to an examination of detached ring size, drift speed, and shedding period. In Section 6, we give the results of numerical simulations and in Section 7 we compare the analytics and numerical results. Finally, we summarize and discuss our results in Section 8. For convenience, we define all the variables both in the text and in the Appendix B. 


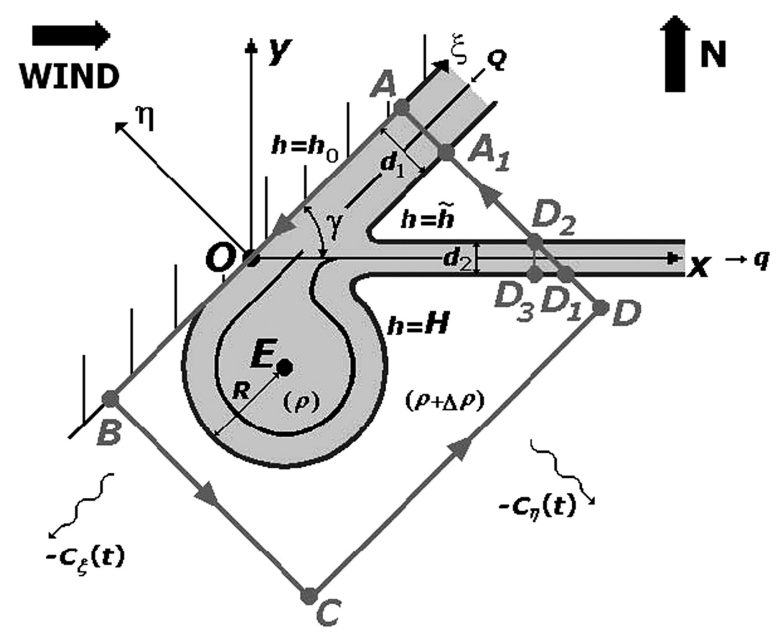

Figure 2. A schematic diagram for a rectilinear slanted coastline. $E$ is the center of the basic eddy (BE). In the (rotated) coordinate system $\xi$ is directed along the coastline, and $\eta$ is directed normal to the coastline. The incoming flux $Q$ flows along the wall whereas the outgoing (retroflected) flux $q$ is directed to the east. The widths of the currents are $d_{1}$ and $d_{2}$, respectively. The "wiggly" arrow indicates the migration of the BE; it results from both the eddy growth, which forces the eddy away from the wall, and from $\beta$, which forces the eddy along the wall. We see that the migration $C_{\eta}(t)$ is primarily due to the growth, whereas $C_{\xi}(t)$ is primarily due to $\beta$. The thick grey line (with arrows) indicates the integration path, $A B C D A ; \tilde{h}$ is the upper layer thickness of the stagnant region wedged in between the upstream and retroflecting current, $h_{0}$ is the upper layer thickness near the wall, and $H$ is the off-shore thickness. The segment $D_{2} D_{3}$ is involved in the expressions containing $\gamma$.

\section{Statement of problem}

As in our preceding papers (ZNa, Zharkov et al., 2010), we consider two models of retroflecting currents. The schematic diagrams are shown in Figure 2 (for a slanted rectilinear coast), and in Figure 3 (for the "kinked" coast i.e., a coastline whose slant changes abruptly within the region of retroflection). In both models, a boundary current with density $\rho$, embedded in an infinitely deep stagnant lower layer whose density is $(\rho+\Delta \rho)$, flows along a slanted coast in a southwestward direction (for the Southern Hemisphere), and then retroflects and heads eastward. The shed rings propagate away from the retroflection region along the coast (in southwestward direction) in the slanted model, and westward along the zonal section of the coast in the kinked model. We bind the coordinate system with the movement of the Basic Eddy (BE, i.e., the eddy formed in the retroflection area) and, in the case of straightforward coast, rotate this system by the slant angle (using the axis $\xi$ and $\eta$, as shown in Fig. 2).

We now consider the physics of the problem taking into account a constant wind stress. This is valid because the area is located close enough to the position of the zero WSC. All the following equations are given in the $\varepsilon^{0}$ order approximation, where the small parameter 


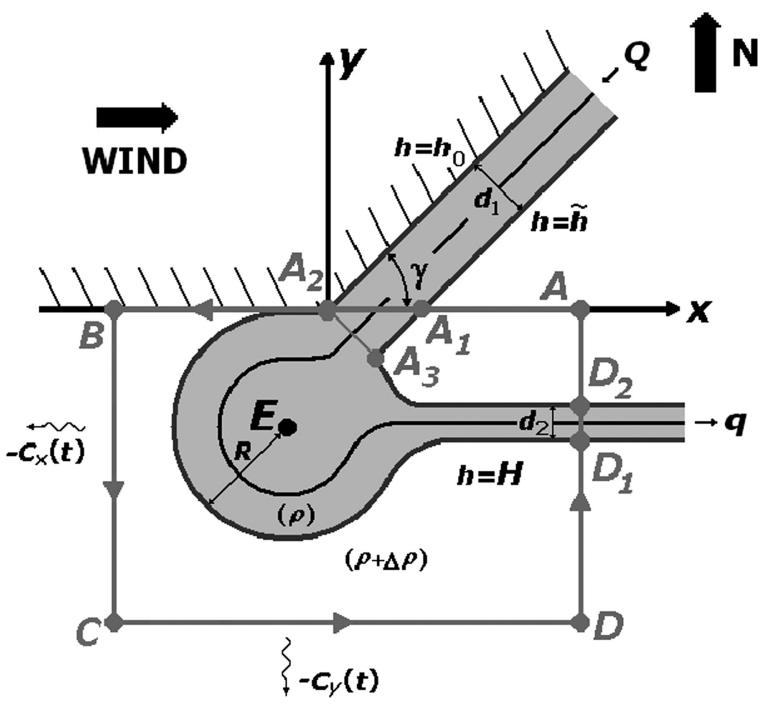

Figure 3. A schematic diagram for a kinked coastline. The basic notations are the same as in Figure 2 but projections of the eddy migration rate are $C_{x}(t)$ and $C_{y}(t)$.

$\varepsilon=\beta R_{d} / f$ characterizes the variation of the Coriolis parameter (due to $\beta$ ) at the scale of the eddy's Rossby radius $R_{d}$ (see, e.g. Arruda et al., 2004). In this approximation, we assume that the BE is circular, and that the incoming and outgoing fluxes are geostrophic in the cross-stream direction. We emphasize here that this does not necessarily mean a puregeostrophy of the outflow (Nof et al., 2011b, see also Van Leeuwen and De Ruijter, 2009).

The arresting condition reflects the balance between the wind stress action on the growing retroflecting eddy and the momentum flux of the upstream jets forcing the eddy to grow in the absence of wind. One of the most important parameters in our models is $\alpha$ (twice the eddy Rossby number). We assume that the BE's orbital speed $v_{\theta}$ is $-\alpha f r / 2$, where $f$ is the Coriolis parameter and $r$ the radius (in the system connected with the BE's center). The parameter $\alpha$ does not exceed unity and, in the case $\alpha=1$, the BE has zero potential vorticity.

\section{a. Conservation of volume}

The integrated volume conservation for the $\mathrm{BE}$ is,

$$
\frac{d V}{d t}=Q-q
$$

Here, $V$ is the volume of the BE; $Q$ and $q$ are the incoming and outgoing mass fluxes (Figs. 2, 3). 


\section{b. Momentum fluxes}

Taking into account the continuity equation and using the slowly varying approximation, we write the momentum equation in along-coast direction in the moving (and tilted) coordinate system for a slanted coast as,

$$
\frac{\partial}{\partial \xi}\left(h u^{* 2}\right)+\frac{\partial}{\partial \eta}\left(h u^{*} v^{*}\right)-f h\left(v^{*}+C_{\eta}\right)=-\frac{g^{\prime}}{2} \frac{\partial}{\partial \xi}\left(h^{2}\right)+\frac{\tau^{\xi}}{\rho} .
$$

In the moving, nontilted system for the kinked coast, the equation in the zonal direction is,

$$
\frac{\partial}{\partial x}\left(h u^{2}\right)+\frac{\partial}{\partial y}(h u v)-f h\left(v+C_{y}\right)=-\frac{g^{\prime}}{2} \frac{\partial}{\partial x}\left(h^{2}\right)+\frac{\tau^{x}}{\rho} .
$$

Here, $u$ and $v$ are the velocities (in the tilted system they are denoted with asterisks); $C_{y}$, $C_{\eta}$ are projections of the BE's epicenter propagation speed on the corresponding axes of fixed coordinate systems; $h$ is the upper layer thickness; $g^{\prime}$ is the reduced gravity; $\tau^{x}, \tau^{\xi}$ are projections of the wind stress on the axes $x$ and $\xi$. Note that the equations in the cross-coast direction are omitted because they involve an unknown force on the wall and are, therefore, of no use here.

\section{Theoretical analysis}

The theoretical analysis in this section follows a traditional approach of integrating the momentum equations ( $2 \mathrm{a}, \mathrm{b}$ ) [see $\mathrm{ZNa}$ ] and the mass conservation equation (1) over a region encompassing the eddy and the retroflection. This way, we obtain an integrated balance of forces over our region of interest without deriving the detailed solution. After that, we expand all variables in powers of $\varepsilon$ and retain only the leading order terms. At the end of our calculations, we will be able to derive a system of differential equations that models the $\mathrm{BE}$ growth as a function of the known input parameters.

\section{a. Integrated momentum balance equations}

We assume that the wind is zonal, i.e., $\tau^{y}=0$. After integrating the equations (2a) systems (2a) and (2b) over the rectangular area $S$ enclosing the BE (grey contours $A B C D$ in Figs. 2, 3) and using Stokes' theorem, we get,

$$
\begin{aligned}
& -\oint_{\varphi} h u^{*} v^{*} d \xi+\oint_{\varphi}\left[h u^{* 2}+\frac{g^{\prime} h^{2}}{2}-f \psi\right] d \eta-\iint_{S}\left[\beta|\psi| \sin \gamma+f h C_{\eta}\right] d \xi d \eta \\
& =\iint_{S} \frac{\tau^{x}}{\rho} \cos \gamma d \xi d \eta
\end{aligned}
$$

for the model of a slanted coastline, and,

$$
-\oint_{\varphi} h u v d x+\oint_{\varphi}\left[h u^{2}+\frac{g^{\prime} h^{2}}{2}-f \psi\right] d y-\iint_{S} f h C_{y} d x d y=\iint_{S} \frac{\tau^{x}}{\rho} d x d y
$$


for the model of a kinked coastline. Here $\gamma$ is the slant angle, $\varphi=\partial S$, and $\psi$ is the streamfunction, defined by $\partial \psi / \partial \eta=-h u^{*}, \partial \psi / \partial \xi=h v^{*}$ in (3a), and by $\partial \psi / \partial y=-h u$, $\partial \psi / \partial x=h v$ in (3b).

\section{b. Estimation of terms in the momentum balance equations}

The forthcoming analysis of the left-hand sides of (3a) and (3b) is analogous to that given in ZNa. First, we show that in (3a) and (3b), we can neglect the terms involving $\left(g^{\prime} h^{2} / 2-\right.$ $f \psi)$. Since $f$ is not constant, the order of $\left(g^{\prime} h^{2} / 2-f \psi\right)$ is $\beta y \psi$ and $\left(g^{\prime} h^{2} / 2-f \psi\right) /\left(h u^{2}\right)$ is $\beta R / f_{0} \sim O(\varepsilon)$. The first term (integration of $h u^{*} v^{*}$ ) in (3a) is also negligible because $v^{*}$ is zero along the wall. In the remaining terms with integration over the contour $\phi$, we leave only integrals over cross-sections of incoming and outgoing current. After some manipulations with integration over oblique cross-sections, we obtain the momentums balances,

$$
F_{1}+F_{2} \cos \gamma-F_{3}-F_{4} \sin \gamma=F_{5} \cos \gamma
$$

for the model of a slanted coastline and,

$$
F_{1} \cos \gamma+F_{2}-F_{3}=F_{5}
$$

for the model of a kinked coastline. Here, $F_{1}$ is the momentum flux of the incoming current, which is defined as $\int_{D_{3}}^{D_{2}} h u^{2} d l$ in (3a), or $\int_{D_{1}}^{D_{2}} h u^{2} d l$ in (3b) (see Figs. 2, 3). $F_{2}$ is the momentum flux of the outgoing current defined as $\int_{A_{1}}^{A} h u^{2} d l$ in (3a), or $\int_{A_{3}}^{A_{2}} h u^{2} d l$ in (3b). $F_{3}$ is the Coriolis force resulting from the growth of the $\mathrm{BE}$ and its resulting off-shore movement, which is $\iint_{S} f h C_{\eta} d \xi d \eta$ in (3a), or $\iint_{S} f h C_{y} d x d y$ in (3b). $F_{4}$ (for the model of a straightforward coastline) is the $\beta$-force resulting from anticyclonic rotation of the $\mathrm{BE}$, defined as $\beta \iint_{S}|\psi| d \xi d \eta$ in (3a). $F_{5}$ is the wind stress force, which is $\iint_{S} \frac{\tau^{x}}{\rho} d \xi d \eta$ in (3a), or $\iint_{S} \frac{\tau^{x}}{\rho} d x d y$ in $(3 \mathrm{~b})$.

As described before, we use the integrated equations $(3 a, b)$ to derive a balance of forces acting on our region of interest. To estimate each term in (3a,b), we connect the BE with the upstream inflow and downstream outflow assuming (via Bernoulli) that the flow speed is constant along the streamline bounding both the eddy and the currents. The BE is assumed circular with a parabolic depth profile (linear velocity $v=\alpha f_{0} r / 2$ ) and a depth $H$ on its boundary, where $f_{0}$ is the absolute value of $f$ at the center of the BE. The incoming/outgoing flows are also assumed to have parabolic depth profiles with velocity match along the bounding streamline.

Without loss of generality, we will now analyze the terms in $(4 a, b)$ in the case of zonal coastline $(\gamma \rightarrow 0)$, for which the calculation of the integrals is the easiest. For convenience, we re-drew this special case (Fig. 4) introducing the new notations and using the original coordinate system $(x, y)$. When we consider the problem for a slanted coastline, we should compare Figs. 4 and 2 (for the case of kink, the analysis is analogous but we compare Figs. 3 and 2). Comparison with Figure 2 shows that $A_{1}$ coincides with $D_{2}$ now, so that instead of 


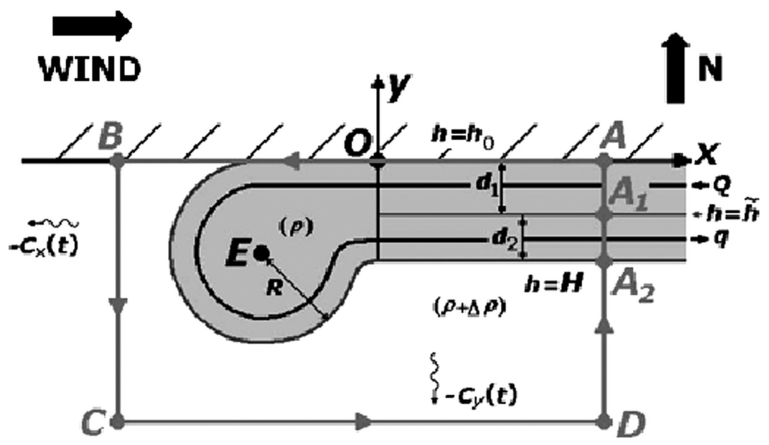

Figure 4. A schematic diagram of the model in the special case of a zonal coastline. Here, we use the coordinate system $(x, y)$. The currents carrying $Q$ and $q$ are separated by the streamline at $x>0$ and $y=-d_{1}$. The 'wiggly' arrows show the migration of the eddy (southward on account of the $\mathrm{BE}$ growth, and westward due to $\beta$ ).

having two segments we now have one combined $A D_{3}$. The integration segment for $F_{2}$ is $A_{1} A_{2}$, so with the error $O(\varepsilon)$, we have

$$
F_{1}=\int_{0}^{d_{1}} h u^{2} d(-y), F_{2}=\int_{d_{1}}^{d_{1}+d_{2}} h u^{2} d(-y), F_{3}=f_{0} C_{y} \iint_{S} h d x d y, F_{4}=\beta \iint_{S}|\psi| d x d y .
$$

Here, $d_{1}$ and $d_{2}$ are the widths of the incoming and retroflected currents. The further analysis of the integrals (5) is analogous to $\mathrm{ZNa}$ and is given in details in Appendix A. We obtain:

$$
\begin{gathered}
F_{1}=\frac{\alpha^{3} f_{0}^{4}}{240 g^{\prime}}\left(2 R^{5}-5 \delta_{1}^{3}+3 \delta_{1}^{5}\right)+\frac{\alpha^{2} f_{0}^{2} h_{0}}{12}\left(R^{3}-\delta_{1}^{3}\right), \\
F_{2}=\frac{\alpha^{3} f_{0}^{4}}{240 g^{\prime}}\left[2 R^{5}-5\left(\delta_{1}^{2}-\delta_{2}^{2}\right) R^{3}-5 \delta_{2}^{3} R^{2}+5 \delta_{1}^{2} \delta_{2}^{3}-2 \delta_{2}^{5}\right]+\frac{\alpha^{2} f_{0}^{2} h_{0}}{12}\left(R^{3}-\delta_{2}^{3}\right), \\
F_{3}=\pi R^{2} f_{0}\left[\frac{\alpha(2-\alpha) f_{0}^{2} R^{2}}{16 g^{\prime}}+H\right] \frac{d R}{d t}, \\
F_{4}=\frac{\pi \alpha \beta f_{0} R^{4}}{8}\left[\frac{\alpha(2-\alpha) f_{0}^{2} R^{2}}{24 g^{\prime}}+H\right]
\end{gathered}
$$

where the variables, $\delta_{1}, \delta_{2}$ are defined by

$$
\delta_{1}=\left[R^{2}-\frac{4 g^{\prime}}{\alpha f_{0}^{2}}\left(\tilde{h}-h_{0}\right)\right]^{1 / 2}, \delta_{2}=\left[R^{2}-\frac{4 g^{\prime}}{\alpha f_{0}^{2}}(\tilde{h}-H)\right]^{1 / 2},
$$


with

$$
\tilde{h}=\left[h_{0}^{2}+\frac{2 f_{0} Q}{g^{\prime}}\right]^{1 / 2}, H=\left[h_{0}^{2}+\frac{2 f_{0}(Q-q)}{g^{\prime}}\right]^{1 / 2} .
$$

Note that (6f) is consistent with geostrophy outside the retroflection area (see Figs. 2, 3). As before, $f_{0}$ is the value of $|f|$ at the BE center, $h_{0}, \tilde{h}, H$ are values of $h$ at the wall, in the wedge between incoming and outgoing fluxes, and outside the retroflection area (where we assume $h_{0}$ to be given), $R$ is the BE radius, $\delta_{1,2}=R-d_{1,2}$, where $d_{1,2}$ are the widths of the incoming and outgoing fluxes (Figs. 2, 3).

Because the $\mathrm{BE}$ area is the main part of the $A B C D$ interior, we find to leading order,

$$
F_{5}=\pi R^{2} \tau^{x} / \rho
$$

The error in (7) is of $O(\varepsilon)$ when we take the retroflection eddy radius to be the mean value. In the worst-case scenario (error-wise), the eddy is arrested by the wind before it reaches its mean size so the error is larger. However, even if the eddy does not grow, the error in (7) is still not more than the difference between the area of a square and the area of a circle inscribed in it, i.e., $(4-\pi) / \pi \sim 0.27$ (strictly speaking, about $0.27 / 2 \sim 0.14$ because the currents are located only to the east of $\mathrm{BE}$, not to the west).

\section{c. Complete system of equations for the BE development}

Substituting (6) and (7) into (4a) and (4b), we obtain the equation for $R(t)$. However, we also have to find $q$ [or, equivalently, $\Phi=(Q-q) / Q$ ] that is also time variable and enters the formulas through the expression for $H$. Using (1), taking the derivative (in time) of (A5) for the BE volume (see Appendix A), and invoking (6f), we obtain,

$$
\begin{aligned}
Q-q= & 2 \pi R\left\{\frac{\alpha(2-\alpha) f_{0}^{2} R^{2}}{8 g^{\prime}}+\left[h_{0}^{2}+\frac{2 f_{0}(Q-q)}{g^{\prime}}\right]^{1 / 2}\right\} \frac{d R}{d t} \\
& -\frac{\pi f R^{2}}{\left[\left(g^{\prime} h_{0}\right)^{2}+2 f_{0} g^{\prime}(Q-q)\right]^{1 / 2}} \frac{d q}{d t},
\end{aligned}
$$

where, as stated before, the BE radius $R$, the depth along its boundary $H$, and the outgoing mass flux $q$ are all functions of time. Our numerics show that the relative contribution of the term with $d q / d t$ is no more than $\sim O(0.01)$, so this term is negligible. With this neglect, we get a quadratic equation for $(Q-q)$ whose physically relevant solution $(Q \geq q)$ is

$$
Q-q=\frac{\mu}{g^{\prime}}\left\{\frac{\alpha(2-\alpha) f_{0}^{2} R^{2}}{8}+f_{0} \mu+\left[\left(f_{0} \mu\right)^{2}+\frac{\alpha(2-\alpha) f_{0}^{3} R^{2} \mu}{4}+\left(g^{\prime} h_{0}\right)^{2}\right]^{1 / 2}\right\},
$$

where $\mu=2 \pi R d R / d t$. 
Now, the system of (4) [with substitution of (6) and (7)] and (8) defines the functions $R(t)$ and $\Phi(t)$ where $\Phi=(Q-q) / Q$ is the ratio of the mass flux going into the rings to incoming mass flux. Recall that the known parameters are $Q, g^{\prime}, f_{0}, \alpha, \beta, \gamma, h_{0}, \tau^{x}$, and $\rho$. Substitution of (7) into (4) and (6) yields a single equation for $R(t)$. As an initial condition at $t=0$, we choose the "complete retroflection" case when the initial BE radius $\left(R_{i}\right)$ coincides with $d_{1}$. Taking $\delta_{1}=0$ in (6e, left), we find

$$
R_{i}=2\left[g^{\prime}\left(\tilde{h}-h_{0}\right) / \alpha\right]^{1 / 2} / f_{0} .
$$

The numerical solution of our system (4, 6-9) is described in Section 4. However, at least for the simplified case ( $\gamma=0$ and $h_{0}=0$ ), we can immediately estimate the magnitude of the wind stress necessary to arrest the BE shedding (which is the aim of our present work). We do this in the next subsection.

\section{d. Arresting wind stress}

To estimate how significant $F_{5}$ is in (4a,b), we compare the right-hand side of (7) with the most significant term (containing $R^{5}$ ) in the sum of $F_{1}$ and $F_{2}$ (see 6a,b); when they are roughly the same then the shedding is arrested because the wind prevents the BE growth. For the case $\gamma=0$ (zonal wall), we should balance $\pi R^{2} \frac{\tau^{x}}{\rho}$ with $\frac{\alpha^{3} f_{0}^{4}}{60 g^{\prime}} R^{5}$, which gives,

$$
\tau^{x}=\frac{\alpha^{3} f_{0}^{4} \rho R^{3}}{60 \pi g^{\prime}}
$$

Next we take $h_{0}=0$ in (6f) and the initial value $R_{i}$ from (9), so that,

$$
R_{i}^{3}=\frac{8}{f_{0}^{3}} \frac{\left(2 f_{0} g^{\prime} Q\right)^{3 / 4}}{\alpha^{3 / 2}} .
$$

Substituting (11) into (10) yields the approximate arresting wind stress,

$$
\tau^{x}=\frac{2}{15 \pi} \alpha^{3 / 2} \rho f_{0}\left[\frac{\left(2 f_{0} Q\right)^{3}}{g^{\prime}}\right]^{1 / 4} .
$$

For $\rho=1010 \mathrm{~kg} \mathrm{~m}^{-3}, f_{0}=0.88 \times 10^{-4} \mathrm{~s}^{-1}, Q=70 \mathrm{~Sv}$, and $g^{\prime}=0.02 \mathrm{~m} \mathrm{~s}^{-2}$, (12) gives,

$$
\tau^{x}=11.7 \alpha^{3 / 2} \mathrm{~Pa} .
$$

In the case of $\alpha=0.1$, which is typical for present day conditions (see Zharkov et al., 2010, page 1008, for their analysis of data from Van Sebille et al., 2009), we get an arresting $\tau^{x}$ of $0.37 \mathrm{~Pa}$, which is close to the stress typical for the Agulhas region during LGM. It follows from (12a) that the effect of wind stress decreases with growing $\alpha$. This result seems strange at first because a growing $\alpha$ means decreasing radius of the BE, implying weaker 
wind force. However, the term describing the wind stress force decreases more slowly than $R^{5}$ so that it stays dominant. Interestingly, for the North Brazil Current (NBC), (12) gives a much smaller arresting stress $\left(\tau^{x}=0.54 \alpha^{3 / 2} \mathrm{~Pa}\right)$, which is not surprising because the NBC is not far from the equator, where the wind stress is much weaker (Kutsuwada et al., 2004, their Fig. 3).

So far, we have estimated the arresting stress, but we still need to determine the eddy growth and mass fluxes using these fairly complicated equations. This will be addressed in the next section.

\section{Basic eddy growth}

\section{a. Slanted (but straight) coastline}

To obtain an analytical solution for $R(t)$ and $\Phi(t)$, we solve the system of equations (4), (6)-(8) using the Runge-Kutta method of the fourth order. We use $Q=70 \mathrm{~Sv}, g^{\prime}=$ $2 \times 10^{-2} \mathrm{~m} \mathrm{~s}^{-2}, \rho=1.02 \times 10^{3} \mathrm{~kg} \mathrm{~m}^{-3}$, and $f_{0}=8.8 \times 10^{-5} \mathrm{~s}^{-1}$ (corresponding to $35^{\circ}$ of latitude). We consider two cases of $h_{0}: 0 \mathrm{~m}$ and $300 \mathrm{~m}$. Also, we use the natural value of $\beta=2.3 \times 10^{-11} \mathrm{~m}^{-1} \mathrm{~s}^{-1}$ and a magnified value $\beta=6 \times 10^{-11} \mathrm{~m}^{-1} \mathrm{~s}^{-1}$. The parameter $\alpha$ is varied between 0.1 and 1.0, and $\gamma$ between $0^{\circ}$ and $90^{\circ}$. Figures 5 and 6 show $R(t)$ and $\Phi(t)$ for the model of a straight slanted coast with $h_{0}=300 \mathrm{~m}, \beta=2.3 \times 10^{-11} \mathrm{~m}^{-1} \mathrm{~s}^{-1}$, $\alpha=0.1$ (panels a, c) and 0.2 (panels b, d), and $\tau^{x}=0$ (panels a, b) and $0.4 \mathrm{~Pa}$ (panels c, d).

As pointed out in $\mathrm{ZNa}$, in the case of a slanted coast without wind stress (Fig. 5a), eddies whose PV is large $(\alpha=0.1)$ cannot grow at the point of retroflection when the slant angle is $45^{\circ}$ or more. Instead, they squeeze into the wall. Figures $5 \mathrm{c}$ and $6 \mathrm{c}$ show that when the wind stress reaches $0.4 \mathrm{~Pa}$, the $\mathrm{BE}$ grows only near the walls whose slants are less than $15^{\circ}$. Also, as expected, the wind decreases the growth rate, so the radii of the detached eddies are smaller in the case of nonzero wind. Small PV (large $\alpha$ ) eddies are not particularly sensitive to wind effects. As can be seen in Figures $5 \mathrm{c}$ and $\mathrm{d}$, the case of $\alpha=0.2$ displays a reduced influence of the wind. Nevertheless, it is seen from Figures $6 \mathrm{c}$ and $\mathrm{d}$ that, even for $\alpha=0.2$, the wind significantly reduces $\Phi$. This should be the case because the volume of a generated eddy is proportional to the fourth power of its radius (Nof and Pichevin, 2001).

In the case when the thickness near the wall $\left(h_{0}\right)$ is zero, the effect of the wind is stronger, so strong PV eddies (with $\alpha=0.1$ ) cannot grow even when the WBC retroflects from a zonal wall $\left(\gamma=0^{\circ}\right)$. We do not show the corresponding figures because, for $\tau^{x}=0.4 \mathrm{~Pa}$, they are simply "empty". However, we will show the numerical results mainly for $h_{0}=0 \mathrm{~m}$ since, in that case, the one-and-a-half-layer structure collapses (owing to viscosity) more slowly than for $h_{0}=300 \mathrm{~m}$.

\section{b. Kinked coastline}

For a kinked coastline configuration (Fig. 3) and in absence of wind (Zharkov et al., 2010), eddies are shed for any $\gamma$ because there are no obstacles on their paths westward. 

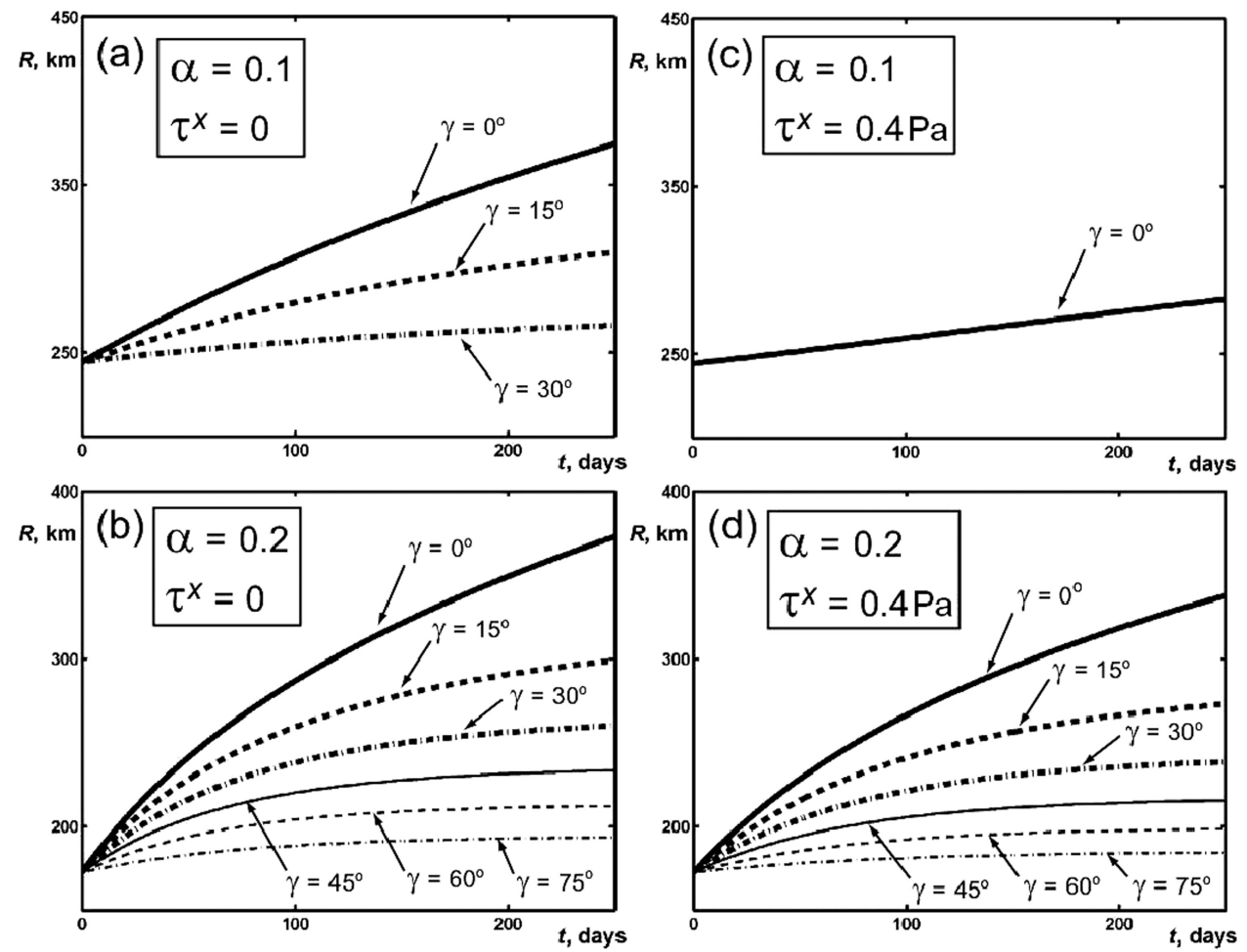

Figure 5. Analytical solution for the base eddy (BE) radius $R$ as a function of time for a straight coast. Here $\alpha=0.1$ (upper panels) and 0.2 (lower panels); wind stress is absent (left panels) and strong ( $0.4 \mathrm{~Pa}$ corresponding to $\sim 12 \mathrm{~m} \mathrm{~s}^{-1}$, right panels). The thick solid, dashed and dot-and-dashed lines correspond to $\gamma=0^{\circ}, 15^{\circ}$, and $30^{\circ}$, respectively; and thin solid, dashed, and dot-and-dashed lines are given for $\gamma=45^{\circ}, 60^{\circ}$ and $75^{\circ}$, respectively.

However, as seen from Figure 7, with 0.4 Pa wind stress, strong PV eddies $(\alpha=0.1)$ can be shed only when the slant of the eastern coast does not exceed $45^{\circ}$; otherwise, no mass flux goes into eddies. For $\alpha=0.2$, the wind affects the growth of the BE only moderately as it does in the case of a straight slanted coast. (The figures for $\Phi$ are analogous and not shown here.)

\section{c. Magnified $\beta$}

When we take the magnified value of $\beta=6 \times 10^{-11} \mathrm{~m}^{-1} \mathrm{~s}^{-1}$ (making the numerics less expensive and reducing the effect of viscosity), we find that, in the straight coastline model, the equatorward $\beta$-force increases, resulting in more intensive interaction of the eddy with the wall. The theoretical results show that when $h_{0}=300 \mathrm{~m}$, eddies with $\alpha=0.1$ squeeze into the straight wall whose slant exceeds $15^{\circ}$ without wind, and for any nonzero slant 

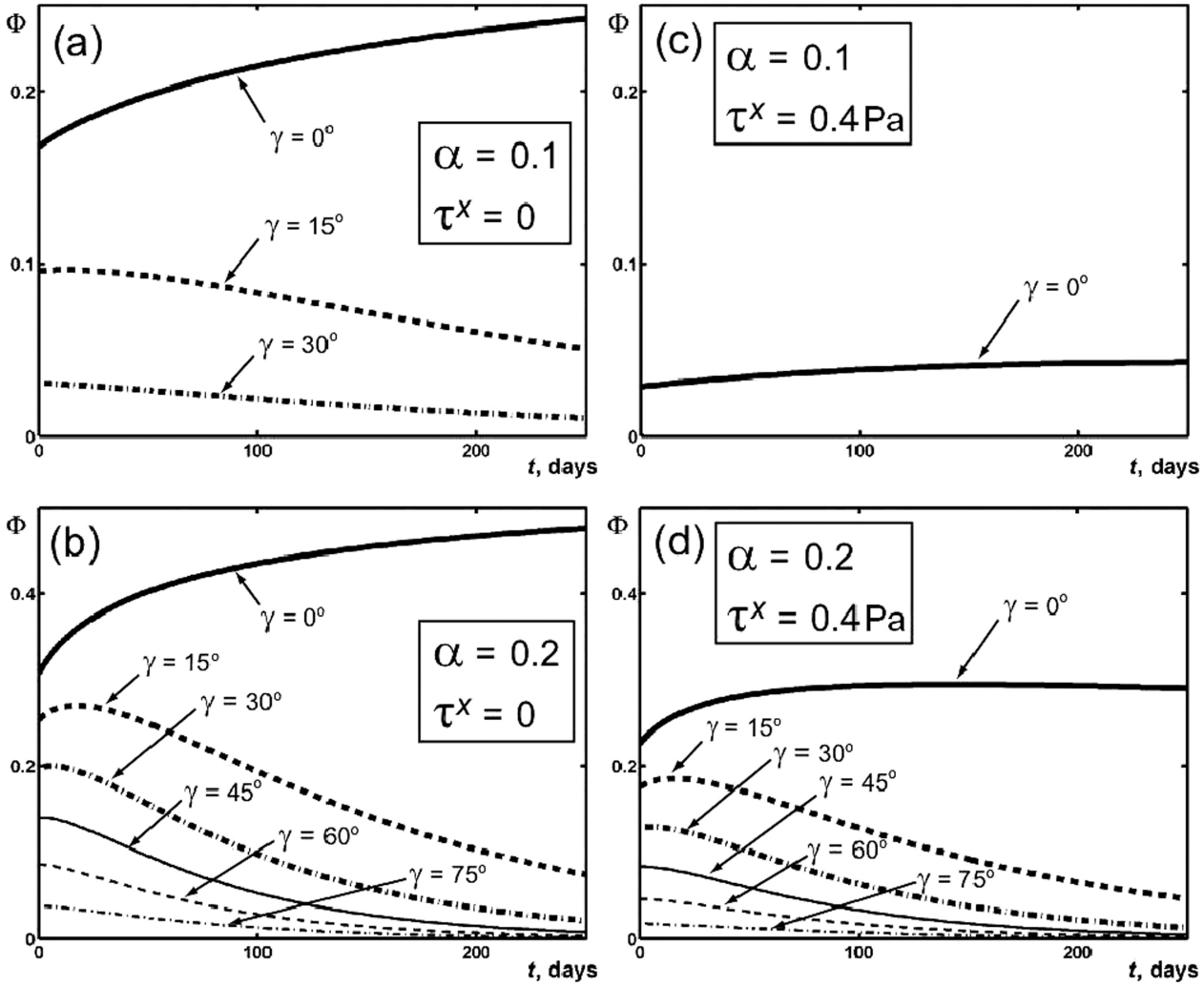

Figure 6. The same as Figure 5 but for the eddy mass flux ratio $\Phi$. Note that for low vorticity $(\alpha=0.1$, upper panels), the mass flux going into the eddies $(\Phi)$ decreases by a factor of 6-8 because of the wind. For high vorticity ( $\alpha=0.2$, lower panels) it decreases by roughly a factor of two (wind stress is $0.4 \mathrm{~Pa}$ ). This figure represents the core of our results-according to the analytical model, the mass flux going into the eddies is almost zero for winds of $12 \mathrm{~m} \mathrm{~s}^{-1}$ and the most common (low vorticity) rings.

with wind strength of $0.4 \mathrm{~Pa}$. If $\alpha$ is 0.2 , squeezing occurs when the slant exceeds $30^{\circ}$, both without and with wind. We note, however, that in our numerics, the viscosity decreases the eddies' spin, so we expect squeezing when $\gamma$ is larger than in the theoretical model. In the model with a kinked coastline, the $\beta$-force does not affect the growth of the $\mathrm{BE}$, so the results are insensitive to the value of $\beta$.

\section{Detachment of rings}

We define below the lower and upper bounds of the final eddy radius and generation period in the same manner that they were defined in ZNb and Zharkov et al. (2010). 

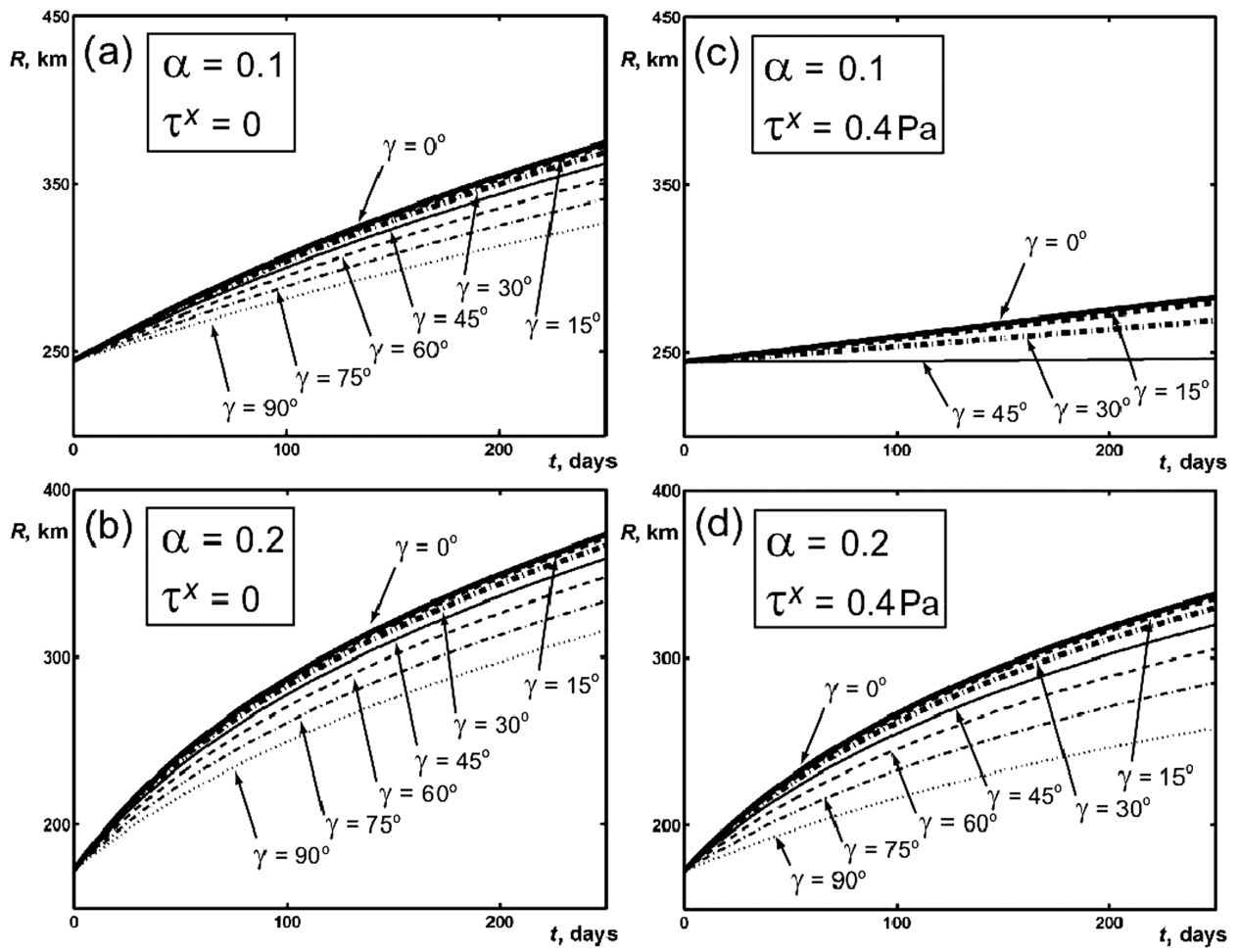

Figure 7. The same as Figure 5, but for the model of a kinked coastline. Here $\gamma$ is the slant of an eastern coastal section, and thin dotted lines are given for $\gamma=90^{\circ}$.

\section{a. Lower bounds}

The lower bound reflects the condition that, at the most, the rings can "kiss" each other but not overlap. Mathematically we get this limit by noting that the generation period for each individual ring is,

$$
t_{f}=\left(2 R_{f}+d\right) /\left|C_{\xi f}\right|
$$

for the model of a slanted coastline, and,

$$
t_{f}=\left(2 R_{f}+d\right) /\left|C_{x f}\right|
$$

for the model of a kinked coastline. Here $d$ is the distance between two consecutive rings, and,

$$
C_{x}=-\beta\left[\frac{\alpha R^{2}}{12}+\frac{2 g^{\prime} H}{(2-\alpha) f_{0}^{2}}\right]
$$


is the ring propagation rate in the zonal direction, $C_{\xi}=C_{x} \cos \gamma$ is the ring propagation rate along the slanted coast, and the subscript $f$ denotes the final value (i.e., the value at the time of detachment). The lower bound for the final eddy size $\left(R_{f l}\right)$ is obtained from the condition of "kissing eddies," i.e., $d=0$. Using (14), we obtain the equation for the lower bound of the rings generation period,

$$
t_{f l}=\frac{24(2-\alpha) f_{0}^{2} R_{f l}}{\beta\left[\alpha(2-\alpha) f_{0}^{2} R_{f l}^{2}+24 g^{\prime} H_{f l}\right] \cos \gamma}
$$

for the slanted coastline, and the same without $\cos \gamma$ for the kinked coastline. Here $H_{f l}=$ $\left[h_{0}^{2}+2 f_{0} \Phi_{l} / g^{\prime}\right]^{1 / 2}$, and equation (15) is solved numerically, implying $R_{f l}=R\left(t_{f l}\right), \Phi_{l}=$ $\Phi\left(t_{f l}\right)$.

\section{b. Upper bounds}

Next, we define the upper bound $\left(R_{f u}\right)$ for the BE's final size and for the generation period $\left(t_{f u}\right)$. This expression implies that, within the shedding period, the ring can propagate at least its own diameter:

$$
\int_{0}^{t_{f u}}\left|C_{\xi}\right| d t=2 R_{f u}
$$

for the slanted coastline, and,

$$
\int_{0}^{t_{f u}}\left|C_{x}\right| d t=2 R_{f u}
$$

for the kinked coastline. The integral-algebraic equations (16) are also solved numerically, implying $R_{f u}=R\left(t_{f u}\right)$ and $\Phi_{u}=\Phi\left(t_{f u}\right)$.

Physically, the upper bound corresponds to the detachment of isolated rings, whereas the lower bound is a condition for the eddy chain formation. So, rings detach and propagate out of the retroflection area only when $R_{f l}$ is indeed less than $R_{f u}$.

\section{c. Analysis of the eddy shedding regimes}

The plots of bounds of the eddy radii, generation periods, corresponding eddy propagation rates, and the averaged (over the generation period) mass fluxes going into eddies are shown in Figure 8 for a straight slanted coast. Here, $h_{0}=300 \mathrm{~m}$ and $\beta=2.3 \times 10^{-11} \mathrm{~m}^{-1} \mathrm{~s}^{-1}$. The left panels are for zero wind stress whereas the right panels are for $\tau^{x}=0.4 \mathrm{~Pa}$. The lower and upper bounds are shown with solid and dashed lines, respectively. Without wind stress, they intersect at the same points for all the considered eddy characteristics (circles in Fig. 8), defining the critical values of the coastal slant. In the supercritical regime, when the slant exceeds this critical value, the shed eddies do not form a chain but rather are re-captured 

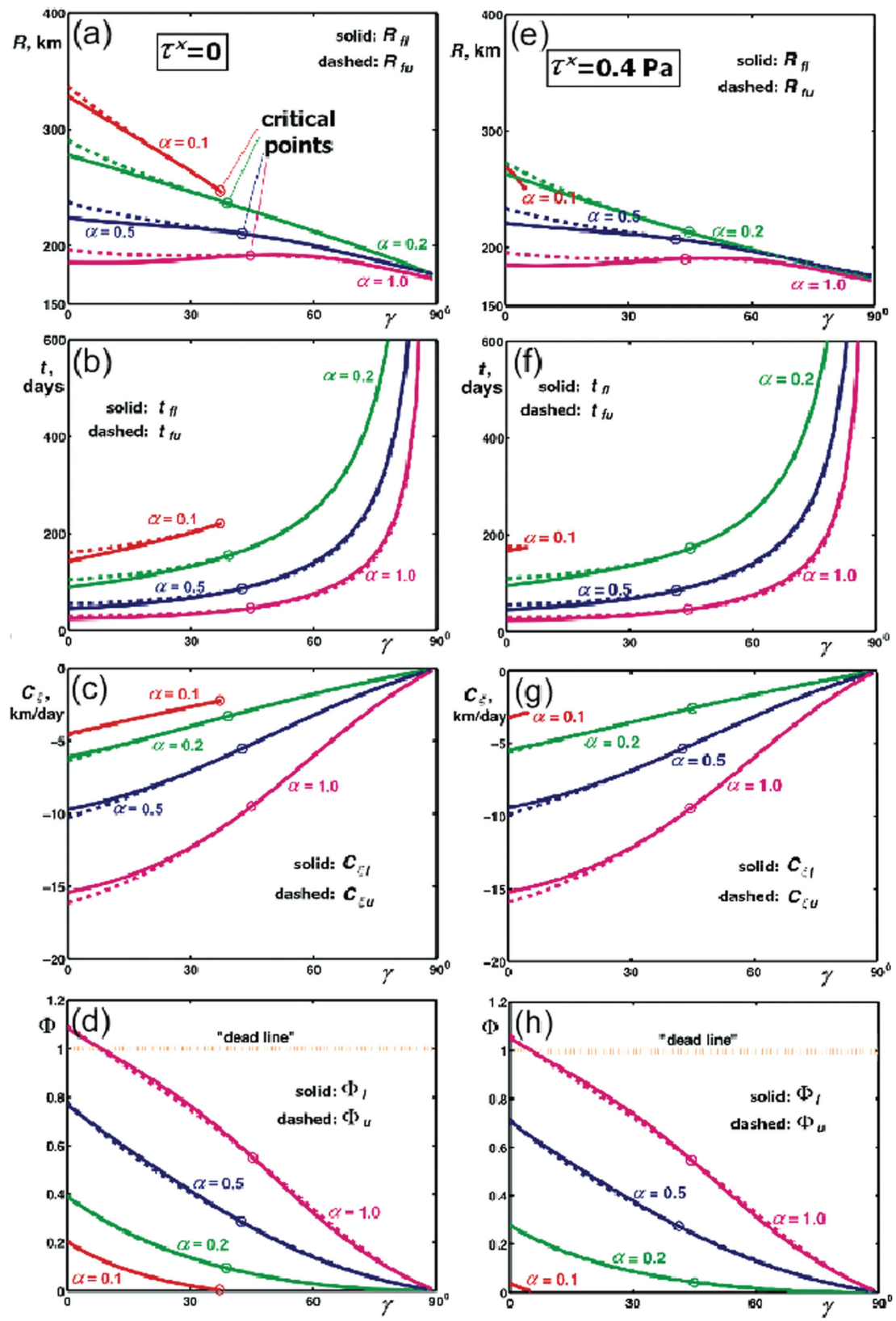

Figure 8. Final (analytical) BE radii ( $R_{f l}$ and $R_{f u}$, panels a, e), ring generation periods ( $t_{f l}$ and $t_{f u}$, panels b, f), ring propagation rates $\left(C_{\xi l}\right.$ and $C_{\xi u}$, panels c, g), and mass flux ratios $\left(\Phi_{l}\right.$ and $\Phi_{u}$, panels $\mathrm{d}, \mathrm{h}$ ) as functions of $\gamma$ for no-wind (left panels) and wind with $\tau^{x}=0.4 \mathrm{~Pa}$ (right panels), for a straightforward slanted coastline model with $h_{0}=300 \mathrm{~m}$ and $\beta=2.3 \times 10^{-11} \mathrm{~m}^{-1} \mathrm{~s}^{-1}$. The critical points (i.e., locations where upper and lower bounds are the same) are circled. They need to be distinguished from the points of line terminations for $\alpha=0.1$ for windy conditions. 
by the retroflected current. For the model with a kinked coast, there is no critical slant, and the regime is subcritical in the sense that detached eddies leave the area of retroflection and form a chain. Also, the dotted horizontal "dead lines" on panels (d) and (h) are drawn for $\Phi=1$, and the sections of curves for $\alpha=1$ above them are in the region of "vorticity paradox" (PV of rings is so small that the system of momentum balance and mass balance equations cannot be satisfied, see $\mathrm{ZNa}$ ). However, it is unnecessary to deal with this paradox here because we consider only strong PV eddies with small $\alpha$.

\section{d. Effect of the wind stress}

The main difference between no-wind and windy conditions is much earlier terminations of curves for $\alpha=0.1$. The wind affects the small vorticity rings mainly by significantly increasing the rings squeezing into the wall. For $h_{0}=0 \mathrm{~m}$ (now shown), the curves for $\alpha=0.1$ are absent (as is the case with the kinked coast as well), meaning that the rings are squeezed in all cases. For the slanted coast model, the $\alpha=0.2$ curves terminate for $\gamma=80^{\circ}$, implying that such rings are also affected by wind, though the effect is significantly weaker.

When the slant is small in the no-kink model or moderate in the model with a kink, the radii of shed small vorticity rings decrease under the windy conditions, so the curves of radii of rings for $\alpha=0.1$ occasionally intersect those for $\alpha=0.2$. Also, the mass flux going into them decreases (and vanishes for those $\gamma$ for which the curves of other parameters terminate, meaning $q=Q$ ). It should be noted that the decrease in mass flux going into the rings is noticeable even for greater values of $\alpha$, meaning that the effect of winds on both the radii of detached rings and periods of detachment leads to a significant decrease in the Agulhas leakage into the South Atlantic.

In contrast, the effect of wind on the critical coastal slant (Fig. 8) is not as clear. For $\alpha=0.1$, there is no intersection of lower and upper bounds of the rings radii and detachment periods, simply because these curves terminate for smaller slants. However, for $\alpha=0.2$, the subcritical range of slant increases under windy conditions, though the distance between the bounds for small slant decreases, implying the extension of nearly critical scenario to the larger slants. In the case of $\alpha=0.2$ and $\gamma=75^{\circ}$, the lower and upper bound curves for the radii of rings re-intersect, meaning the restoration of the subcritical regime for slants exceeding $75^{\circ}$. However, the relative difference in $R_{f l}$ and $R_{f u}$ is $\sim O\left(10^{-5}\right)$ and the mass flux going into the rings is very small, so that the aforementioned "restoration" hardly makes any sense. We note here that for $h_{0}=0 \mathrm{~m}$, such effects for $\alpha=0.2$ do not appear and, as expected, the subcritical range of coastal slant is shortened in windy conditions.

\section{Numerical simulations}

\section{a. Model setup}

As in our previous studies (ZNab, Zharkov et al., 2010), we use a modified version of the earlier Bleck and Boudra (1986) reduced gravity isopycnic model with a passive lower 
layer and the Orlanski (1976) second-order radiation conditions for the open boundary. The basin size is taken to be $3200 \times 1600 \mathrm{~km}^{2}$. The coastline is modeled by either a fixed straightforward boundary whose slant is taken to be $15^{\circ}$ and $45^{\circ}$, or by a western section with a slant of $15^{\circ}$ and a zonal section about $1840 \mathrm{~km}$ long (kinked coastline). We also consider the continental termination, modeled by the meridional western wall and the slanted eastern one. The walls are taken to be slippery. We adapt a sinusoidal profile of the WSC with maximal $\tau^{x}(0.4$ or $0.8 \mathrm{~Pa})$ at about $500 \mathrm{~km}$ to the south from the retroflection area (as it should be in reality) and zero $\tau^{x}$ near the equator (about $4100 \mathrm{~km}$ to the north from the retroflection area). In this case, the difference between the peak of wind stress and stress in the retroflection area is relatively small (about 2\%-3\%) and cannot significantly affect our results.

Other parameters that we use are $g^{\prime}=2 \times 10^{-2} \mathrm{~m} \mathrm{~s}^{-2}, f_{0}=8.8 \times 10^{-5} \mathrm{~s}^{-1}, Q=70 \mathrm{~Sv}$, $\beta=2.3 \times 10^{-11} \mathrm{~m}^{-1} \mathrm{~s}^{-1}$ (realistic) or $6 \times 10^{-11} \mathrm{~m}^{-1} \mathrm{~s}^{-1}$ (magnified), and $h_{0}=0 \mathrm{~m}$ or $300 \mathrm{~m}$. We have run all the experiments for about 700 days. For most of the experiments, we have chosen the magnified value of $\beta$, which accelerates ring detachment and makes our runs more economical. Note that increasing the ring propagation rate compensates for the deceleration by viscosity.

The experiment begins with turning on an outflow at $t=0$; the numerical source is an open channel containing streamlines parallel to the slanted wall in the incoming current and horizontal in the outgoing flow. The initial velocity profile across the channel is linear, and the thickness profile is parabolic. We have chosen the initial PV of outflows such that the starting values of $\alpha$ are 0.1 and 0.2 . The spatial and temporal resolutions that were used in our preceding works are increased because the inclusion of wind stress requires larger values of Laplacian viscosity coefficient for stability of the calculations. The numerical parameters are a time step of $20 \mathrm{~s}$, a grid step of $3.33 \mathrm{~km}$, and a Laplacian viscosity coefficient of $\nu=700 \mathrm{~m}^{2} \mathrm{~s}^{-1}$ for the model of a slanted coast and $\nu=800 \mathrm{~m}^{2} \mathrm{~s}^{-1}$ for a kinked coast and coastal termination (also, for some no-wind simulations, we take $\nu=500 \mathrm{~m}^{2} \mathrm{~s}^{-1}$ ). These coefficients are the minimum possible choices for the stability of long-time simulations. Unfortunately, the stability of calculations significantly decreases in the wind conditions, so the diffusion speed ( $v$ divided by the grid size) is $21 \mathrm{~cm} \mathrm{~s}^{-1}$ in simulations with slanted coast and $24 \mathrm{~cm} \mathrm{~s}^{-1}$ with a kinked coast. Such values appear high but are still small compared to the rings' orbital speed (about $2 \mathrm{~m} \mathrm{~s}^{-1}$ ), so they are adequate. Chang and Oey (2010) used larger grid size $(10 \mathrm{~km})$ and smaller viscosity $\left(100 \mathrm{~m}^{2} \mathrm{~s}^{-1}\right)$ but their wind stress was much smaller too so the tendency of features to break-up was much smaller as well. Also, we believe that our numerics are still significantly nonlinear. For example, according to Dijkstra and De Ruijter (2001a,b), viscous effects become dominating for their forced model of Agulhas retroflection when $\nu$ is at least of the order $1650 \mathrm{~m}^{2} \mathrm{~s}^{-1}$, and this conclusion is also in agreement with that of Boudra and Chassignet (1988).

Despite increased resolution, the parameter $\alpha$ is altered by viscosity almost in the same way as it was in the simulations described in ZNb. Here, in the simulations with $h_{0}=0 \mathrm{~m}$, the parameter $\alpha$ increases from its initial value of 0.1 , so that its average over the period 

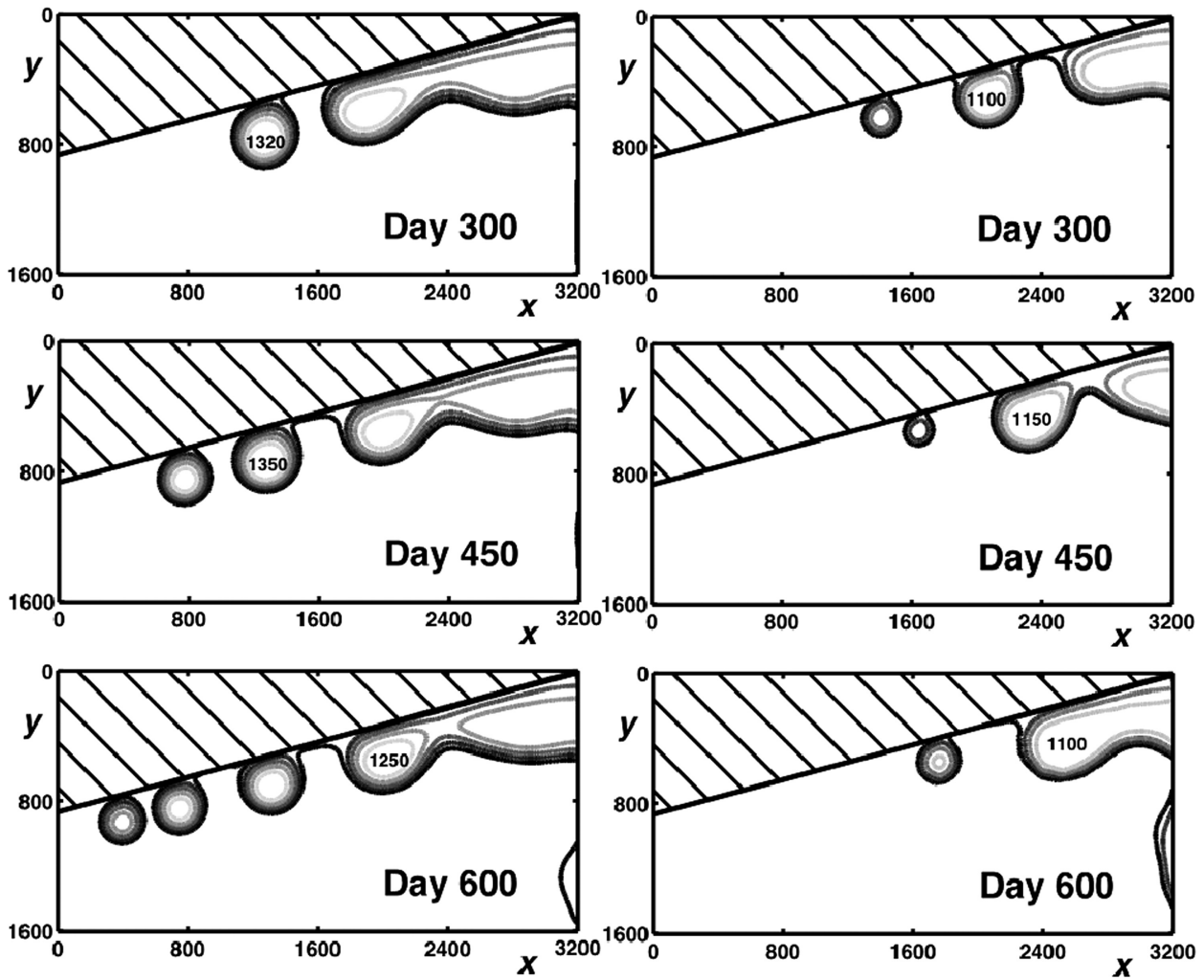

Figure 9. Numerical simulations for a straight coast with $\gamma=15^{\circ}, h_{0}=0 \mathrm{~m}, \beta=6 \times 10^{-11} \mathrm{~m}^{-1} \mathrm{~s}^{-1}$, $\nu=700 \mathrm{~m}^{2} \mathrm{~s}^{-1}$. Left panels: no wind (experiment SC01 in Table 1). Right panels: strong wind, $\tau^{x}=0.8 \mathrm{~Pa}$ (experiment SC02 in Table 1). To compensate for the numerical frictional effects, which accumulate over time, we use double the stress used in the analytics $(0.4 \mathrm{~Pa})$.

of simulation is about $0.21-0.22$. In the simulations when the initial value of $\alpha$ is 0.2 , it slightly increased to about $0.23-0.24$. In the simulations with $h_{0}=300 \mathrm{~m}$ and $\alpha=0.1, \alpha$ does not increase as much, so its averaged value is about $0.17-0.18$. As noted by $\mathrm{ZNb}$, the averaged value of $\alpha$ does not strongly depend on its initial value. Therefore, it is difficult to determine the desirable value of this parameter numerically. Rather, we assume that in all our simulations, the results should be in agreement with the theoretical predictions for $\alpha=0.2$. Hence, the effect of the wind in the $\tau=0.4$ Pa case should not be very strong, though still noticeable, in the numerics. To compensate for the expected weakening of the wind effect owing to the growth of $\alpha$, we also perform simulations with maximal wind stress of $0.8 \mathrm{~Pa}$. The simulations for an initial $\alpha$ of 0.2 are preferable to those of 0.1 because the period of ring detachment decreases with growing $\alpha$ (see Fig. 8f for $\gamma \leq 5^{\circ}$ ).

Some snapshots of our experiments are shown in Figures 9-11. The parameters that we chose are listed in Table 1. 

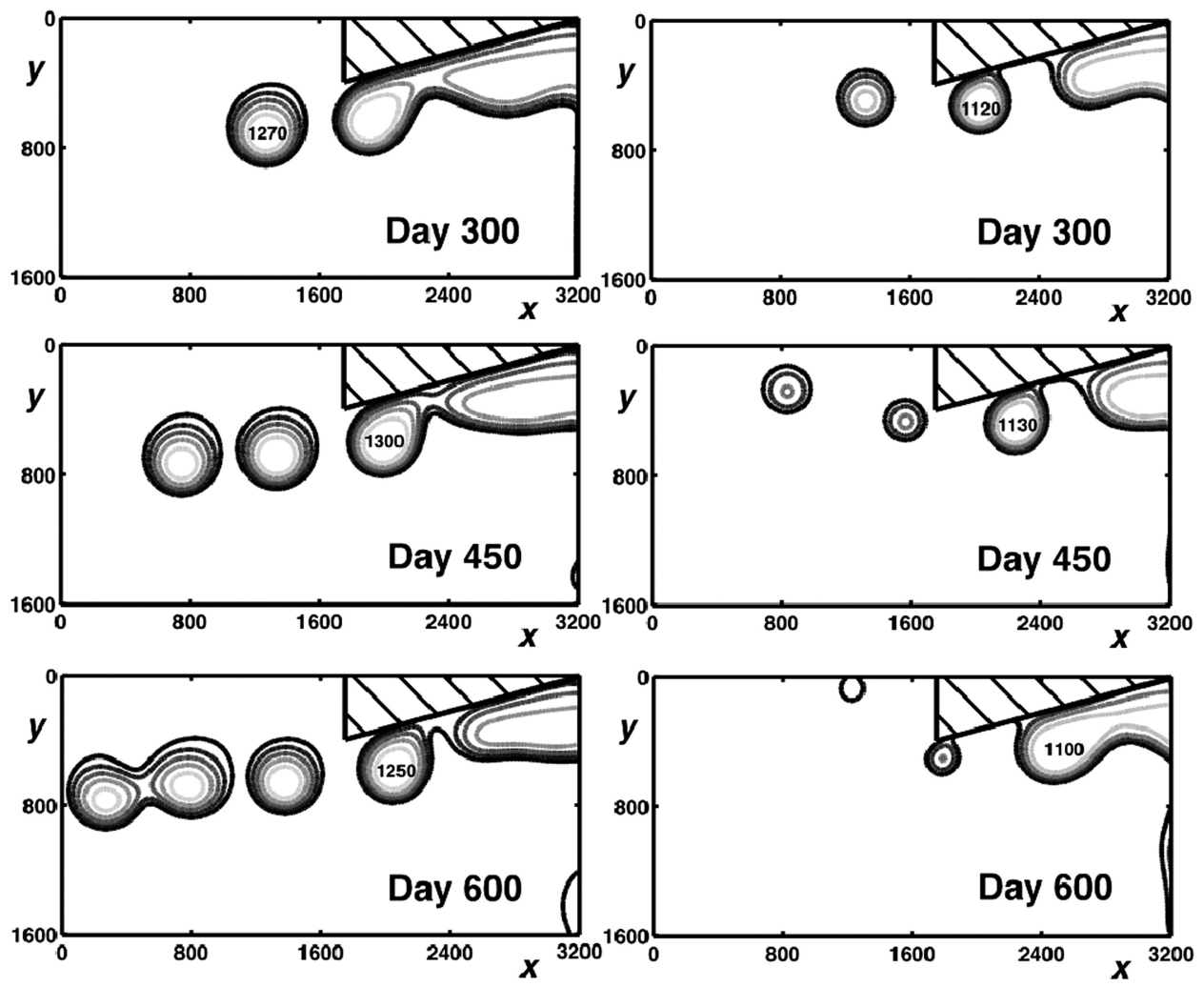

Figure 10. Numerical simulations for continental termination with slant of an eastern coast $\gamma=15^{\circ}$. Here $h_{0}=0 \mathrm{~m}, \beta=6 \times 10^{-11} \mathrm{~m}^{-1} \mathrm{~s}^{-1}, \nu=800 \mathrm{~m}^{2} \mathrm{~s}^{-1}$. Left panels: no wind (experiment TC01 in Table 1). Right panels: strong wind, $\tau^{x}=0.8 \mathrm{~Pa}$ (experiment TC02 in Table 1).

\section{b. Slanted coastline}

Figure 9 shows plots for the 300th, 450th, and 600th days of simulations for a $15^{\circ}$ straight coast slant, zero $h_{0}$, magnified value of $\beta$, and an initial $\alpha$ of 0.2 . The left panels show the no-wind conditions, whereas the right panels are for $\tau^{x}=0.8 \mathrm{~Pa}$. The viscosity coefficient is $700 \mathrm{~m}^{2} \mathrm{~s}^{-1}$, which is minimal for stability of calculations in both cases. The scale on the coordinate axes is in kilometers, and the lines of constant upper layer thickness are given through 200 meter increments. Also, the maximal thickness (in meters) is marked. It is seen that when there is no wind, a chain of eddies forms gradually, as should be the case because a $15^{\circ}$ slant is subcritical (see ZNb). With strong wind (Fig. 9, right panels), a chain of eddies does not form, and only one eddy is shed from the retroflection area. Note that, although the right panels are analogous to those in the case of no-wind conditions for supercritical slant (in the sense that the eddy shedding is nearly arrested in both cases), there is actually a difference between these two cases. In the supercritical case, the eddy detaches from the retroflection area but propagates very slowly, decays gradually, and is usually re-captured 

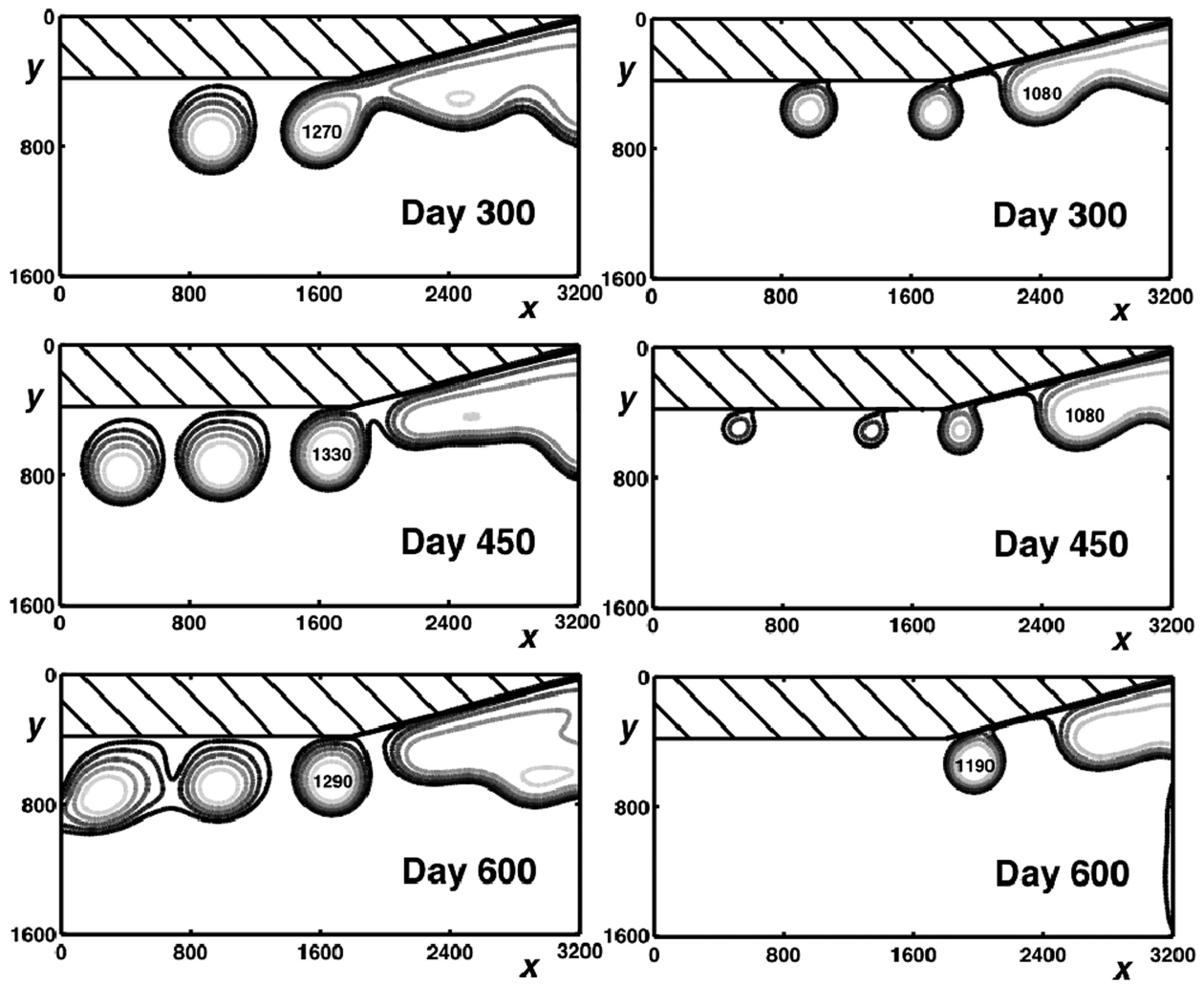

Figure 11. Numerical simulations for a kinked coast with an eastern section slant $\gamma=15^{\circ}$. Here $h_{0}=0 \mathrm{~m}, \beta=6 \times 10^{-11} \mathrm{~m}^{-1} \mathrm{~s}^{-1}, \nu=800 \mathrm{~m}^{2} \mathrm{~s}^{-1}$. Left panels: no wind (experiment $\mathrm{KC} 01$ in Table 1). Right panels: strong wind, $\tau^{x}=0.8 \mathrm{~Pa}$ (experiment $\mathrm{KC} 02$ in Table 1 ).

Table 1. Parameters used in the numerical experiments shown in Figure 9-11. The experiments for slanted coastline, terminated coastline, and kinked coastline are denoted by SC, TC, and $\mathrm{KC}$, respectively.

\section{Shown in}

Experiments Figure

Common parameters

Specific parameters

\begin{tabular}{|c|c|c|c|}
\hline SC01 & Fig. 9 & \multirow{6}{*}{$\begin{array}{l}g^{\prime}=2.0 \times 10^{-2} \mathrm{~m} \mathrm{~s}^{-2} \\
f_{0}=8.8 \times 10^{-5} \mathrm{~s}^{-1} \\
\beta=6.0 \times 10^{-11} \mathrm{~m}^{-1} \mathrm{~s}^{-1} \\
Q=70 \mathrm{~Sv} \\
h_{0}=0 \mathrm{~m} \\
\gamma=15^{\circ} \\
\alpha=0.2 \\
\text { Horizontal resolution: } \Delta x=\Delta y=3.33 \mathrm{~km} \\
\text { Time step: } \Delta t=20 \mathrm{~s}(\text { time step) } \\
\text { Basin size: } 3200 \times 1600 \mathrm{~km}^{2}\end{array}$} & $\nu=700 \mathrm{~m}^{2} \mathrm{~s}^{-1} ; \tau^{x}=0 \mathrm{~Pa}$ \\
\hline $\mathrm{SC} 02$ & Fig. 9 & & $\nu=700 \mathrm{~m}^{2} \mathrm{~s}^{-1} ; \tau^{x}=0.8 \mathrm{~Pa}$ \\
\hline TC01 & Fig. 10 & & $\nu=800 \mathrm{~m}^{2} \mathrm{~s}^{-1} ; \tau^{x}=0 \mathrm{~Pa}$ \\
\hline TC02 & Fig. 10 & & $\nu=800 \mathrm{~m}^{2} \mathrm{~s}^{-1} ; \tau^{x}=0.8 \mathrm{~Pa}$ \\
\hline $\mathrm{KC} 01$ & Fig. 11 & & $\nu=800 \mathrm{~m}^{2} \mathrm{~s}^{-1} ; \tau^{x}=0 \mathrm{~Pa}$ \\
\hline $\mathrm{KC} 02$ & Fig. 11 & & $\nu=800 \mathrm{~m}^{2} \mathrm{~s}^{-1} ; \tau^{x}=0.8 \mathrm{~Pa}$ \\
\hline
\end{tabular}


by the meandering outgoing flux. In the case of strong wind, on the other hand, the ring is not re-captured but rather squeezed onto the wall and finally destroyed. Indeed, ZNb noted that termination of lines depicting both the lower and upper bounds of the rings radii (in the case of very small $\alpha$ ) indicates squeezing of eddies. This is probably the case for windy conditions. Of course, when the coast slant is nearly critical (or even supercritical) and the wind is strong enough, these effects act together to decrease/prevent the shedding.

The ring propagation rate decreases with increasing wind speed, and for the somewhat artificial condition of very strong winds $(0.8 \mathrm{~Pa}$, introduced merely to compensate for the numerical friction), it practically vanishes. In this case, the retroflection shifts upstream, leaving the shed ring at the same place to be ultimately destroyed by the wind. For the cases of wind with $\tau^{x}=0.4 \mathrm{~Pa}$, which is typical for glacials, the analytics predict that detached eddies (for which $\alpha=0.1$ ) will be destroyed. The numerics, on the other hand, show that, after 700 days of simulation, only two of four detached eddies are destroyed, and the thickness of the last detached eddy decreases by about $10 \%$. This could be an effect of increased $\alpha$.

\section{c. Coastal termination}

We suspect that the wind not only directly destroys detached eddies, but also pushes them to the left (looking downwind) into the wall. To examine this hypothesis, we conduct numerical experiments with a triangular continental termination not far from the retroflection area (Fig. 10). Here, we are obliged to take $\nu=800 \mathrm{~m}^{2} \mathrm{~s}^{-1}$ to ensure the stability of calculations. Nevertheless, it is seen that, with no wind, the rings continue moving southwestward after passing the termination (although their radii are larger than those of the eddies shown in Figure 9 and, staring from about the 560th day of simulation, the first eddy is gradually captured by the second one). As expected, with strong wind, eddies turn to the northwest (or even north-northwest) after passing the termination, and they do not decay as quickly as the eddies shown in Figure 9. This is in agreement with our assumption and with Nof et al. (2011a).

\section{d. Kinked coastline}

We also consider the case of a kinked coastline with a zonal western section and an eastern section slanted by $15^{\circ}$ (Fig. 11). Here, we again are obliged to take $\nu=800 \mathrm{~m}^{2} \mathrm{~s}^{-1}$. Nevertheless, we see that rings propagate along the zonal coast faster than along the slanted coast (as should be the case) but the rate of their decay under the wind effect is stronger. This should be the case as well because the rings encounter the wind "head-on", so-to-speak. As a result, as seen in the right panel, more than one eddy near the zonal coast is destroyed at the same time. On the other hand, the eddy that is left near the kink is locked there with almost no propagation and a smaller decaying rate. It is either squeezed onto the kink or is re-captured by the next BE advancing from the area of retroflection. Note, however, that it is not very clear how often the locking effect will be repeated in experiments with varying 
input parameters. Similar effects can be seen for an initial value of $\alpha=0.1$, but the rings decay a bit more slowly, probably because of longer periods of detachment.

\section{e. Varying viscosity and upper layer depth}

In our runs with no wind using a smaller viscosity coefficient $\left(\nu=500 \mathrm{~m}^{2} \mathrm{~s}^{-1}\right)$, the differences with our simulations shown in the left panels of Figure 9-11 are not very significant. The main difference is that the capturing of the first eddy by the second one in simulation with coastal termination occurs later than seen in Figure 10, when the first eddy is already passing through the left border of the calculation area. Therefore, the capturing of one eddy by another becomes more common with increasing viscosity.

All of the effects of the wind stress mentioned above are significantly diminished in simulations with $h_{0}=300 \mathrm{~m}$ (not shown). This is most likely because the wind acts on a deeper column of water. The quantitative effect of the wind with $\tau^{x}=0.4 \mathrm{~Pa}$ is seen only in the simulation with a kinked coast. The destroying effect of the wind with $\tau^{x}=0.8 \mathrm{~Pa}$ is not as strong as in the case $h_{0}=0 \mathrm{~m}$, so eddies lose only about one half of their intensity when approaching the border of the calculation area. The shift in the direction of propagation after passing the continental termination is weak.

\section{A detailed comparison of the theoretical modeling and the numerical simulations}

We begin by giving the results for the conditions associated with the experiment described in Figure $9\left(\gamma=15^{\circ}, h_{0}=0 \mathrm{~m}\right.$, and $\left.\beta=6 \times 10^{-11} \mathrm{~m}^{-1} \mathrm{~s}^{-1}\right)$. For simplicity, we use the value of $\alpha$ averaged over the full period of the simulation, namely, 0.23 for the no-wind conditions (left panels of Fig. 9), and 0.25 for $\tau^{x}=0.8 \mathrm{~Pa}$ (right panels), keeping in mind that the initial $\alpha$ is 0.2 in both cases. Note, however, that, according to our analytical model, for $\tau^{x}=0.8 \mathrm{~Pa}$, the magnified value of $\beta$, and $\alpha=0.2$, shedding of rings is not expected because the inertia associated with the vorticity is small compared to the force exerted by the wind. For the averaged value of $\alpha=0.25$, shedding can occur theoretically even though the mass flux going into the rings is small. So, for such a "balance" between shedding and arresting, we can compare the theoretical values for $\alpha=0.25$ with the numerical values only for a short time, immediately after detachment.

The agreement in the radii of detached eddies is excellent. The theoretical value of $R_{f}$ (calculated as mean of $R_{f l}$ and $R_{f u}$ ) is $225 \mathrm{~km}$ for no-wind and $202 \mathrm{~km}$ for $\tau^{x}=0.8 \mathrm{~Pa}$. In the numerics, we obtain $230 \mathrm{~km}$ and $197 \mathrm{~km}$, respectively. So, even the volumes of eddies are expected to be close to each other in the theoretical model and in the numerics. However, the viscous dissipation in the numerics seems to be so strong that the ring propagation rates in the numerics are about half those in the analytics. The absolute numerical values of $C_{\xi f}$ are $4.2 \mathrm{~km} \mathrm{day}^{-1}$ with no-wind and $3.7 \mathrm{~km} \mathrm{day}^{-1}$ with wind, instead of 9.6 and $7.0 \mathrm{~km} \mathrm{day}^{-1}$ in the theoretical model. In accordance with this, the mean periods of shedding in the numerics (155 and 140 days, respectively) are much larger than the theoretical values of 77 and 46 days. 
Finally, the averaged $\Phi$ is significantly smaller in the numerics than in the analytics. Again, the viscous dissipation is the probable cause. In addition, $\Phi$ is proportional to the fifth power of the radius, implying a large accumulation of errors. For windy conditions, we obtain a negative value $(\Phi=-0.008)$ instead of the theoretical value 0.048 for averaged $\alpha$. (Recall that, for initial $\alpha=0.2$, we are beyond the "arresting point" theoretically, so that $\Phi$ is zero). For no-wind conditions, the theoretical value is 0.145 and, in the numerics, we obtain 0.058 .

\section{Conclusions and discussion}

We consider the wind effect on the Agulhas retroflection during glacials using both analytical and numerical models. Present-day winds are approximately $0.08 \mathrm{~Pa}$ and we took the glacial wind stress to be moderately strong, about $0.4 \mathrm{~Pa}$ (Figs. 5-8). The most informative results are displayed in Figures 6 and 9, which show the dramatic reduction in the eddies' mass transport for $\tau=0.4 \mathrm{~Pa}, \alpha=0.1$ in theory and very strong numerical shut-off for $\tau=0.8 \mathrm{~Pa}, \alpha=0.2$. For zero upper layer thickness along a zonal wall, the arresting wind stress is found, theoretically, to be,

$$
\tau^{x}=0.042 \alpha^{3 / 2} \rho f_{0}\left[\left(2 f_{0} Q\right)^{3} / g^{\prime}\right]^{1 / 4} .
$$

(All the variables are defined earlier in the text and are also given in the Appendix B.) This condition corresponds to an integrated wind stress (over the eddy) that is equal and opposite to the upstream momentum flux, so there is no eddy growth.

Typical winds for the Agulhas region during glacial times (with stress of $0.4 \mathrm{~Pa}$ ) significantly affect the typically moderately strong Agulhas rings $(\alpha=0.1)$ but, with increasing $\alpha$, the influence of wind quickly decreases and becomes negligible for $\alpha>0.2$. The disappearance of the lines for $\alpha=0.1$ in Figures 5-7 for glacial wind conditions (right panels) and termination of curves for $\alpha=0.1$ in Figure 8 (right panels) show that rings with weak vorticity squeeze into the wall rather than grow before detaching (as they do when the wind is light or moderate and the coast is not strongly slanted). Also, the effect of wind decreases slightly with increasing upper layer thickness.

The above findings are in agreement with our numerical simulations. Despite the reasonable spatial resolution, the numerical runs with wind require relatively large viscosity coefficients. Their values are, nevertheless, acceptable because the relatively coarse resolution implies the diffusion speed of about $20-25 \mathrm{~cm} \mathrm{~s}^{-1}$, which is still small compared to the rings' orbital speed (about $2 \mathrm{~m} \mathrm{~s}^{-1}$ ). Unfortunately, this high (though acceptable) viscosity that we had to use increased the initialized value 0.1 of $\alpha$ in the weak vorticity case, so the averaged value that we considered was $\sim 0.2$ for all the runs. For the very same reason, the wind effect on the retroflection in the numerics was not very noticeable for $\tau^{x}=0.4 \mathrm{~Pa}$, so, to compensate for the growth in $\alpha$, we did runs with $0.8 \mathrm{~Pa}$. We also used the magnified value of $\beta$ (gradient of the Coriolis parameter) to make our runs more economical and to increase the rings propagation rate, compensating again for the slowing down effect of viscosity. 
The numerics show that the wind indeed tends to destroy the detached rings by squeezing them onto the wall. This is in agreement with the findings of Nof et al. (2011a) showing that rings subject to zonal westerly winds drift to the northeast. The result is valid in both the straight and the kinked coast cases. In the latter case, rings that detach near the kink are occasionally locked there and are re-captured by the retroflected current. When the rings are detached near the coastal termination, they turn northwestward after entering the open ocean. Also, both the theoretical results and the numerics show that the effect of the wind is stronger when the rings' thickness along their rim is small. This is simply because the wind acts on less water in this case.

Numerically verifying the weakening of the wind influence with growing $\alpha$ is difficult because this parameter is quickly reduced during the numerical runs and becomes $0.2-0.3$ even for the high vorticity cases. However, in reality, $\alpha$ is indeed quite small $(\sim 0.1)$. As shown in the analytics, we expect the wind to affect the Agulhas ring shedding during glacials, and even shut it down completely (Fig. 6, upper panel). Note that in our model, the radii of the eddies with small $\alpha$ are too large (about $250-300 \mathrm{~km}$ ), and the periods of detachment are too long (about 6-7 months). It can be argued, perhaps, that we obtained the strong effect of wind on such unnatural eddies because their propagation speeds are low (about $4 \mathrm{~km} \mathrm{day}^{-1}$ ). However, this argument is not valid because the period of real shedding of Agulhas rings is about 2 months (see subsection 1a for references), and the distance between their centers is about $300-350 \mathrm{~km}$, so their propagation rate is about $5-6 \mathrm{~km} \mathrm{day}^{-1}$, which is not far from our modeled value. The theoretical and numerical radii are in very good agreement; however, the numerical eddies propagation rates and mass fluxes (going to eddies) are significantly smaller, and shedding periods are significantly larger probably because of accumulated errors and the damping effect of viscosity.

Note that we do not really know the general wind direction in the Agulhas region during glacials, so we cannot speak about the actual squeezing of rings into the coast or about change in their direction after entering the Atlantic. It is also not quite clear why, in the numerics, the stability decreases with increasing wind stress particularly because similar stresses tend to stabilize the currents (see, e.g., Griffiths et al., 1982; Shi and RØed, 1999). However, in our case, the main destabilization probably comes not from the upstream and downstream currents but rather from the region of retroflection itself where the gradients of velocity are strong. The wind tries to compress this area, so the stability decreases because the gradients increase.

A question arises about the direction in which the ejected fluid goes during the eddy squeezing process. If the fluid goes downstream as a part of direct Agulhas leakage (see, e.g., Doglioli et al., 2006; Van Sebille et al., 2010), then the Indian Ocean water influx into the South Atlantic would not be strongly reduced. However, in theoretical papers about the eddy-wall interaction (e.g., Shi and Nof, 1994), it is shown that an anticyclonic eddy leaks fluid equatorwards. So, in the case of Agulhas rings, the leaked fluid should return to the retroflection area rather than flowing into the Atlantic. In our numerics, the direct dissipation of eddies is very strong, probably because the scale of leakage is comparable to the scale 
of viscous boundary layer (or even smaller than that). Nevertheless, in our Figures 9-11 (especially in windy conditions-right panels), some leakage of the detached eddies is seen. It is directed northeastward along a slanted coast. Therefore, even if, during glacials, there was a portion of water leaking to the Atlantic from squeezing Agulhas eddies, it was very little.

In summary, we note that the increasing wind stress during glacials probably have contributed significantly to eddy-shedding-shutoff. However, the significant equatorward shift of the zero WSC (and subtropical front, see Beal et al., 2011, ZNb) could be another factor that strongly affected the position of the Agulhas retroflection.

Acknowledgments. The study was supported by NASA Doctoral Fellowship Grant NNG05GP65H; LANL/IGPP Grant (1815); NSF (OCE-0752225, OCE-9911342, OCE-0545204, OCE-0241036), BSF (2006296), and NASA (NNX07AL97G). Wilton Arruda is supported by Conselho Nacional de Desenvolvemento Cientifico e Tecnologico (CNPq), of the Ministry of Science and Technology of Brazil, under grant 201627/2010-8. We are grateful to Steve Van Gorder for helping in the numerical simulations. We also thank Donna Samaan for helping in preparation of the manuscript and Kathy Fearon for assistance in improving the style. We also express our appreciation to two anonymous referees for their constructive criticisms that helped in improving our paper.

\section{APPENDIX A}

\section{Derivation of formulas for $F_{i}(i=1, \ldots, 4)$ in the case $\gamma=0$}

In our analysis below, we first obtain the formulas $u(y)$ and $h(y)$ across the incoming $\left(0<-y<d_{1}\right)$ and outgoing $\left(d_{1}<-y<d_{1}+d_{2}\right)$ fluxes. We assume $u(y)$ to be linear in both flows (but allowing the jump of velocity at their vertical interface, where $y=-d_{1}$ ), satisfy the Bernoulli at the rims of incoming and outgoing currents, and the continuity of velocities along the streamlines passing through the cross-section connecting the currents and the $\mathrm{BE}(x=0)$. Because the angular velocity of the BE is $\alpha f / 2$, we take approximately $u\left(-d_{1}-d_{2}\right)=\alpha f_{0} R / 2$ and $u(0)=-\alpha f_{0} R / 2$ where $f_{0}$ is the absolute value of $f$ at the center of BE. Finally, the expressions for $u(y)$ are found to be,

$u=\frac{\alpha f_{0}}{2}(-y-R), 0 \leq-y \leq d_{1} ; \quad u=\frac{\alpha f_{0}}{2}\left(-y+R-d_{1}-d_{2}\right), d_{1}<-y \leq d_{1}+d_{2}$.

The functions $h(y)$ can be derived from $u(y)$, assuming both flows to be geostrophic (with the error of the order $\varepsilon$ ), and satisfying the condition of continuity of $h$ at the vertical interface of the currents. As a result,

$$
\begin{aligned}
& h=-\frac{\alpha f_{0}^{2}}{4 g^{\prime}} y(2 R+y)+h_{0}, 0<-y \leq d_{1}, \\
& h=\frac{\alpha f_{0}^{2}}{4 g^{\prime}}\left\{-y\left[2\left(d_{1}+d_{2}-R\right)+y\right]+2 d_{1}\left(2 R-d_{1}-d_{2}\right)\right\}+h_{0}, d_{1}<-y \leq d_{1}+d_{2},
\end{aligned}
$$

where $h_{0}$ is value of $h$ at the zonal wall $(y=0)$. 
Next, we shall use the expressions for the downstream and upstream volume fluxes,

$$
Q=\int_{0}^{-d_{1}} h u d y, q=-\int_{-d_{1}}^{-\left(d_{1}+d_{2}\right)} h u d y .
$$

Substitution of (A1) and (A2) into (A3) yields the equations for $d_{1}$ and $d_{2}$ whose solutions are $d_{1,2}=R-\delta_{1,2}$, where $\delta_{1,2}$ are given by (6e) [invoking (6f)]. It is easy to show that $h=\tilde{h}$ at $y=-d_{1}$ and $h=H$ at $y=-\left(d_{1}+d_{2}\right)$, as should be the case. Finally, after substituting (A1), (A3), (6e) and (6f) into (5) for $F_{1}$ and $F_{2}$ and some algebra, we find (6a) and $(6 b)$.

The leading-order expressions for $F_{3}$ and $F_{4}$ will be obtained using the polar coordinate system $(r, \theta)$. Next, we derive an expression for the thickness of the upper layer inside the $\mathrm{BE}$ from the equation, $\partial h / \partial r=\left(v_{\theta}^{2} / r+f v_{\theta}\right) / g^{\prime}$ and the boundary condition $h(R)=H$, to be,

$$
h(r)=\frac{\alpha(2-\alpha) f_{0}^{2}}{8 g^{\prime}}\left(R^{2}-r^{2}\right)+H .
$$

The volume of the circular eddy together with (A4) yields,

$$
V=\pi R^{2}\left[\frac{\alpha(2-\alpha) f_{0}^{2} R^{2}}{16 g^{\prime}}+H\right] .
$$

Assuming now that $d R / d t$ is the propagation speed of the BE's epicenter perpendicular to the coast (and that the eddy itself touches the coastline), and neglecting the variability of $f$ inside the BE area, we find (6c) from (5) and (A5). Finally, defining $F_{4}$ in the same manner as in Nof (1981), we substitute (A4) into the formulas $\psi=\int_{R}^{r} v_{\theta} h d r$ and find $F_{4}=2 \pi \beta \int_{0}^{R} r|\psi| d r$, giving (6d).

\section{APPENDIX B}

\section{List of abbreviations and symbols}

$\mathrm{BE}$ - basic eddy

$C_{D A}$ - coefficient of interfacial drag in the atmosphere

$C_{\xi}, C_{\eta}$ - eddy migration rates in the rotated coordinate system

$C_{\xi f}$ - value of $C_{\xi}$ after detachment

$C_{\xi l}, C_{\xi u}$ - values of $C_{\xi f}$ for eddies with radii $R_{f l}, R_{f u}$, respectively

$C_{x}, C_{y}, C_{x f}, C_{x l}, C_{x u}$ - analogues to $C_{\xi}, C_{\eta}, C_{\xi f}, C_{\xi l}, C_{\xi u}$, respectively, in the

Cartesian coordinate system

$d$ - distance between two consecutive eddies

$d_{1}$ - width of incoming current

$d_{2}$ - width of retroflected current 
$f$ - the Coriolis parameter

$f_{0}$ - absolute value of the Coriolis parameter at the BE center

$F_{1}$ - force of incoming current

$F_{2}$ - force of outgoing current

$F_{3}$ - Coriolis force of the BE growth

$F_{4}-\beta$-force resulting from the $\mathrm{BE}$ rotation

$F_{5}-$ wind stress force

$g^{\prime}$ - reduced gravity

$h$ - upper layer thickness

$H$ - upper layer thickness outside the retroflection area

$h_{0}$ - upper layer thickness at the wall

$\widetilde{h}$ - upper layer thickness in the stagnant wedge situated between the incoming and retroflected currents

LGM - Last Glacial Maximum

$\mathrm{PV}$ - potential vorticity

$Q$ - mass flux of the incoming current

$q$ - mass flux of the retroflected current

$r$ - polar radius (in the system connected with the BE center)

$R$ - radius of the eddy (a function of time)

$R_{d}$ - Rossby radius of the $\mathrm{BE}$

$R_{f}$ - radius of detached eddy

$R_{f l}, R_{f u}$ - lower and upper bounds of $R_{f}$

$R_{i}$ - initial radius of the $\mathrm{BE}$

$S$ - area of integration (enclosing the BE)

ST - Sverdrup Transport

$\mathrm{Sv}-$ Sverdrup $\left(10^{6} \mathrm{~m}^{3} \mathrm{~s}^{-1}\right)$

$t$ - time

$t_{f}-$ period of the eddies generation

$t_{f l}, t_{f u}$ - lower and upper bounds of $t_{f}$

$u, v$ - coordinates of the particle velocity vector

$v_{\theta}$ - orbital velocity of the BE

$V$ - volume of the BE

$x, y-$ zonal and meridional coordinate axes in the moving system

WBC - western boundary current

WSC - wind stress curl

$\mathrm{ZNa}-$ Zharkov and Nof (2008a)

$\mathrm{ZNb}-$ Zharkov and Nof (2008b)

$\alpha$ - twice the eddy Rossby number

$\beta$ - meridional gradient of the Coriolis parameter

$\gamma$ - slant of the coastline (in the model of straightforward coast), or slant of the eastern section of coastline (in the model with kink) 
$\delta_{1,2}$ - differences between $R$ and $d_{1,2}$

$\Delta \rho$ - difference between densities of lower and upper layer

$\varepsilon$ - small parameter defined as $\beta R_{d} / f$

$\varphi$ - integration contour ( $A B C D$ ) enclosing the area $S$

$\Phi$ - ratio of the mass flux going into the rings to incoming mass flux

$\Phi_{l}, \Phi_{u}$ - values of $\Phi$ for eddies with radii $R_{f l}, R_{f u}$, respectively

$\nu$ - viscosity coefficient in numerics

$\theta$ - angle in polar coordinate system (connected with the BE center)

$\rho$ - upper water layer density

$\rho_{A}-$ air density

$\tau^{x}, \tau^{y}, \tau^{\xi}, \tau^{\eta}$ - wind stress coordinates

$\xi, \eta$-axes of rotated moving coordinate system

\section{REFERENCES}

Anderson, R. F., S. Ali, L. I. Bradtmiller, S. H. H. Nielsen, M. Q. Fleisner, B. E. Anderson and L. H. Burckle. 2009. Wind-driven upwelling in the Southern Ocean and the deglacial rise in atmospheric $\mathrm{CO}_{2}$. Science, 323, 1443-1448.

Arruda, W. Z., D. Nof and J. J. O'Brien. 2004. Does the Ulleung eddy owe its existence to $\beta$ and nonlinearities? Deep-Sea Res., 51, 2073-2090.

Beal, L. M., W. P. M. De Ruijter, A. Biastoch, R. Zahn and SCOR/WCRP/IAPSO Working Group 136. 2011. On the role of the Agulhas system in ocean circulation and climate. Nature, 472, 429-436.

Berger, W. H. and G. Wefer. 1996. Expeditions Into the Past: Paleoceanographic Studies in the South Atlantic, Springer-Verlag, Berlin-Heidelberg, 35-156.

Biastoch, A., C. W. Böning and J. R. E. Lutjeharms. 2008. Agulhas leakage dynamics affects decadal variability in Atlantic overturning circulation. Nature, 456, 489-492.

Biastoch, A., C. W. Böning, F. U. Schwarzkopf and J. R. E. Lutjeharms. 2009. Increase in Agulhas leakage due to poleward shift of Southern Hemisphere westerlies. Nature, 462, 495-499.

Bleck, R. and D. B. Boudra. 1986. Wind-driven spin-up in eddy-resolving ocean models formulated in isopycnic and isobaric coordinates. J. Geophys. Res., 91, 7611-7621.

Boudra, D. B. and E. R. Chassignet. 1988. Dynamics of Agulhas retroflection and ring formation in a numerical model. Part I: The vorticity balance. J. Phys. Oceanogr., 18, 280-303.

Butzin, M., M. Prange and G. Lohmann. 2005. Radiocarbon simulations for the glacial ocean: The effects of wind stress, Southern Ocean sea ice and Heinrich events. Earth and Planet. Sci. Lett., $235,45-61$.

Byrne, A. D., A. L. Gordon and W. F. Haxby. 1995. Agulhas eddies: A synoptic view using Geosat ERM data. J. Phys. Oceanogr., 25, 902-917.

Casal, T. G. D., L. M. Beal, R. Lumpkin and W. E. Johns. 2009. Structure and downstream evolution of the Agulhas Current system during a quasi-synoptic survey in February-March 2003. J. Geophys. Res., 114, C03001, doi: 10.1029/2008JC004954.

Chang, Y-L. and L.-Y. Oey. 2010. Why can wind delay the shedding of Loop Current eddies? J. Phys. Oceanogr., 40, 2481-2494.

Dencausse, D., M. Arhan and S. Speich. 2010a. Spatio-temporal characteristics of the Agulhas Current Retroflection. Deep-Sea Res., 57, 1392-1405.

-2010b. Routes of Agulhas rings in the southeastern Cape Basin. Deep-Sea Res., 57, 1406-1421. 
De Ruijter, W. P. M., H. M. Van Aken, E. J. Beier, J. R. E. Lutjeharms, R. P. Matano and M. W. Schouten. 2004. Eddies and dipoles around South Madagascar: formation, pathways and largescale impact. Deep-Sea Res., 51, 383-400.

Dijkstra, H. A. and W. P. M. De Ruijter. 2001a. On the physics of the Agulhas Current: steady retroflection regimes. J. Phys. Oceanogr., 31, 2971-2985.

2001b. Barotropic instabilities of the Agulhas Current system and their relation to ring formation. J. Mar. Res., 59, 517-533.

Doglioli, A.M., M. Veneziani, B. Blanke, S. Speich and A. Griffa. 2006. A Lagrangian analysis of the Indian-Atlantic interocean exchange in a regional model. Geophys. Res. Lett., 33, L14611, doi: 10.1029/2006GL026498.

Esper, O., G. J. M. Versteegh, K. A. F. Zonneveld and H. Willems. 2004. A palynological reconstruction of the Agulhas Retroflection (South Atlantic Ocean) during the Late Quaternary. Global Planet. Change, 41, 31-62.

Flores, J. A., R. Gersonde and F. J. Sierro. 1999. Pleistocene fluctuations in the Agulhas Current Retroflection based on the calcareous plankton record. Mar. Micropaleontol., 37, 1-22.

Franzese, A. M., S. R. Hemming, S. L. Goldstein and R. F. Anderson. 2006. Reduced Agulhas leakage during the Last Glacial Maximum inferred from an integrated provenance and flux study. Earth Planet. Sci. Lett., 250, 72-88.

Gordon, A. L., J. R. E. Lutjeharms and M. L. Gründlingh. 1987. Stratification and circulation at the Agulhas Retroflection. Deep-Sea Res., 34, 565-599.

Griffiths, R. W., P. D. Killworth and M. E. Stern. 1982. Ageostrophic instability of ocean currents. J. Fluid Mech., 117, 343-377.

Howard, W. R. and W. L. Prell. 1992. Late quaternary surface circulation of the southern Indian Ocean and its relationship to orbital variation. Paleoceanogr., 7, 79-117.

Kutsuvada, K., M. Kasahara and K. Aoki. 2004. Gridded surface wind-stress product over the world ocean constructed by satellite scatterometer data and its compassion with NWP products. Gayana, $68,348-354$.

Lutjeharms, J. R. E. 2006. The Agulhas Current, Springer-Verlag, Berlin-Heidelberg-NY, 330 pp.

Morey, S. L., M. A. Bourassa, X. J. Davis, J. J. O’Brien and J. Zavala-Hidalgo. 2005. Remotely sensed winds for episodic forcing of ocean models. J. Geophys. Res., 110, doi:10.1029/2004JC002338.

Nan, F., Z. He, H. Zhou and D. Wang. 2011. Three long-lived anticyclonic eddies in the northern South China Sea. J. Geophys. Res., 116, C05002, doi:10.1029/2010JC006790.

Nof, D. and T. Pichevin. 1996. The retroflection paradox. J. Phys. Oceanogr., 26, 2344-2358. 2001. The ballooning of outflows. J. Phys. Oceanogr., 31, 3045-3058.

Nof, D., Y. Jia, E. Chassignet and A. Bozec. 2011a. Fast wind-induced migration of Leddies in the South China Sea. J. Phys. Oceanogr., 41, 1683-1693.

Nof, D., V. Zharkov, W. Arruda, T. Pichevin, S. Van Gorder and N. Paldor. 2011b. A note on "The steadiness of separating meandering currents" by Peter Jan Van Leeuwen and Will P. M. De Ruijter. J. Phys. Oceanogr., (submitted).

Orlanski, I. 1976. A simple boundary condition for unbounded hyperbolic flows. J. Comput. Phys., 21, 251-269.

Otto-Bliesner, B. L., E. C. Brady, G. Clauzet, R. Tomas, S. Levis and Z. Kothavala. 2006. Last glacial maximum and Holocene climate in CCSM3. J. Climate, 19, 2526-2544.

Peeters, F. J. C., R. Acheson, G.-J. A. Brummer, W. P. M. De Ruijter, R. R. Schneider, G. M. Ganssen, E. Ufkes and D. Kroon. 2004. Vigorous exchange between the Indian and Atlantic oceans at the end of the past five glacial periods. Nature, 430, 661-665.

Pether, J. 1994. Molluscan evidence for enhanced deglacial advection of Agulhas water in the Benguela Current, off southwestern Africa. Paleogeogr. Paleoclimatol. Paleoecol., 111, 99-117. 
Pichevin, L., M. Cremer, J. Giraudeau and P. Bertrand. 2005. A 190 ky record of lithologenic grainsize on the Namibian slope: Forging a tight link between past wind-strength and coastal upwelling dynamics. Mar. Geol., 218, 81-96.

Pichevin, T., S. Herbette and F. Floc'h. 2009. Eddy formation and shedding in a separating boundary current. J. Phys. Oceanogr., 39, 1921-1934.

Rau, A. J., J. Rogers, J. R. E. Lutjeharms, J. Giraudeau, J. A. Lee-Thorp, M.-T. Chen and C. Waelbroeck. 2002. A 450-kyr record of hydrological conditions on the western Agulhas Bank Slope, south of Africa. Mar. Geol., 180, 183-201.

Rouault, M., P. Penven, and B. Pohl. 2009. Warming in the Agulhas Current system since the 1980's. Geophys. Res. Lett., 36, L12602, doi:10.1029/2009GL037987.

Schouten, M. W., W. P. M. De Ruijter, P. J. Van Leeuwen and J. R. E. Lutjeharms. 2000. Translation, decay and splitting of Agulhas rings in the south-eastern Atlantic Ocean. J. Geophys. Res., 105, 21913-21925.

Shi, C. and D. Nof. 1994. The destruction of lenses and generation of wodons. J. Phys. Oceanogr., 24, 1120-1136.

Shi, X.B. and L.P. RØed. 1999. Frontal instabilities in a two-layer, primitive equation ocean model. J. Phys. Oceanogr., 29, 948-968.

Shulmeister, J., I. Goodwin, J. Renwick, K. Harle, L. Armand, M. S. McGlone, E. Cook, J. Dodson, P. P. Hess, P. Mayeswski and M. Curran. 2004. The Southern Hemisphere westerlies in the Australasian sector over the last glacial cycle: a synthesis. Quatern. Intern., 118-119, 23-53.

Van Aken, H. M., A. K. Van Veldhoven, C. Veth, W. P. M. De Ruijter, P. J. Van Leeuwen, S. S. Drijfhout, C. P. Whittle and M. Rouault. 2003. Observations of a young Agulhas ring, Astrid, during MARE in March 2000. Deep-Sea Res., 50, 167-195.

Van Leeuwen, P. J. and W. P. M. De Ruijter. 2009. On the steadiness of separating meandering currents. J. Phys. Oceanogr., 39, 437-448.

Van Sebille, E., A. Biastoch, P. J. Van Leeuwen and W. P. M. De Ruijter. 2009. A weaker Agulhas Current leads to more Agulhas leakage. Geophys. Res. Lett., 36, L03601, doi:10.1029/2008GL036614.

Van Sebille, E., P. J. Van Leeuwen, A. Biastoch and W. P. M. De Ruijter. 2010. On the fast decay of Agulhas rings. J. Geophys. Res., 115, C0310, doi: 10.1029/2009JC005585.

Weijer, W., W. P. M. De Ruijter, H. A. Dijkstra and P. J. Van Leeuwen. 1999. Impact of interbasin exchange on the Atlantic Overturning Circulation. J. Phys. Oceanogr., 29, 2266-2284.

Weijer, W., W. P. M. De Ruijter, A. Sterl and S. S. Drijfhout. 2002. Response of the Atlantic overturning circulation to South Atlantic sources of buoyancy. Global Planet. Change, 34, 293311.

Xiu, P., F. Chai, L. Shi, H. Xue and Y. Chao. 2010. A census of eddy activities in the South China Sea during 1993-2007. J. Geophys. Res., 115, C03012, doi: 10.1029/2009JC005657.

Zharkov, V. and D. Nof. 2008a. Retroflection from slanted coastlines- circumventing the "vorticity paradox". Ocean Sci., 4, 293-306.

- 2008b. Agulhas ring injection into the South Atlantic during glacials and interglacials. Ocean Sci., 4, 223-237.

Zharkov, V., D. Nof and W. Weijer. 2010. Retroflection from a double-slanted coastline: a model for the Agulhas leakage variability. Ocean Sci., 6, 997-1011.

Received: 5 April, 2011; revised: 3 November, 2011. 